\title{
A novel testis-specific protein, PRAMEY, is involved in spermatogenesis in cattle
}

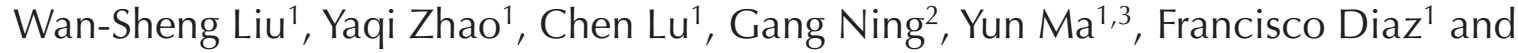 \\ Michael O'Connor ${ }^{1}$ \\ ${ }^{1}$ Department of Animal Science, Center for Reproductive Biology and Health (CRBH), College of Agricultural \\ Sciences, ${ }^{2}$ Microscopy and Cytometry Facility, The Huck Institutes of the Life Sciences, The Pennsylvania State \\ University, University Park, Pennsylvania, USA and ${ }^{3}$ College of Life Science, Xinyang Normal University, Xinyang, \\ Henan, China \\ Correspondence should be addressed to W-S Liu; Email: wul12@psu.edu
}

\begin{abstract}
Preferentially expressed antigen in melanoma (PRAME) is a cancer/testis antigen that is predominantly expressed in normal testicular tissues and a variety of tumors. The function of the PRAME family in spermatogenesis remains unknown. This study was designed to characterize the Y-linked PRAME (PRAMEY) protein during spermatogenesis in cattle. We found that PRAMEY is a novel male germ cell-specific, and a germinal granule-associated protein that is expressed in spermatogenic cells during spermatogenesis. The intact PRAMEY protein $(58 \mathrm{kDa})$ was detected in different ages of testes but not in epididymal spermatozoa. A PRAMEY isoform (30 kDa) was highly expressed only in testes after puberty and in epididymal spermatozoa. This isoform interacts with PP1 $\gamma 2$ and is likely the mature protein present in the testes and sperm. Immunofluorescent staining demonstrated that PRAMEY was located predominantly in the acrosome granule of spermatids, and in acrosome and flagellum of spermatozoa. Immunogold electron microscopy further localized the PRAMEY protein complex to the nucleus and several cytoplasmic organelles, including the rough endoplasmic reticulum, some small vesicles, the intermitochondrial cement, the chromatoid body and the centrioles, in spermatogonia, spermatocytes, spermatids and/or spermatozoa. PRAMEY was highly enriched in and structurally associated with the matrix of the acrosomal granule (AG) in round spermatids, and migrated with the expansion of the AG during acrosomal biogenesis. While the function of PRAMEY remains unclear during spermatogenesis, our results suggest that PRAMEY may play an essential role in acrosome biogenesis and spermatogenesis.

Free Chinese abstract: A Chinese translation of this abstract is freely available at http://www.reproduction-online.org/ content/153/6/847/suppl/DC2.

Free Spanish abstract: A Spanish translation of this abstract is freely available at http://www.reproduction-online.org/ content/153/6/847/suppl/DC3.

Reproduction (2017) 153 847-863
\end{abstract}

\section{Introduction}

Spermatogenesis is a complex cellular transformation process within the seminiferous tubules of the testis, which can be divided into three functional phases: mitosis, meiosis and spermiogenesis. During the last phase - spermiogenesis, haploid round spermatids are transformed into the complex structure of spermatozoa that are released into the seminiferous tubule lumen.

Spermiogenesis begins with the formation of the acrosome (AC) (Kawa et al. 2006). Acrosomal biogenesis starts with the Golgi phase, in which numerous small proacrosomal granules emerge from the Golgi apparatus (Susi et al. 1971, Anakwe \& Gerton 1990, Berruti \& Paiardi 2011). These small vesicles fuse into a large single AG. Subsequently, the dense AG expands and flattens over the surface of the nucleus (Grootegoed et al. 1995). During the second half of spermiogenesis, the AC undergoes extensive morphological changes, which results in different shapes between species.

Numerous germ cell-specific antigens are expressed in the testis during spermatogenesis. Interestingly, many of these antigens are absent or expressed at a very low level in normal somatic tissues. However, they are expressed at a high level in various types of tumors (Cheng et al. 2011). Due to the restricted expression pattern in testis and a variety of cancers, these antigens are designated as cancer/testis antigens (CTAs). Some CTAs are also expressed in the ovary and trophoblast cells of the early embryo (Simpson et al. 2005). During spermatogenesis, many CTAs are expressed transiently at a specific stage (e.g. synaptonemal complex 
protein 1, SCP1) (Meuwissen et al. 1992), while some are expressed at several stages of spermatogenesis (e.g. trophinin, TRO and preferentially expressed antigen in melanoma (Prame)-like 1, PRAMEL1) (Saburi et al. 2001, Mistry et al. 2013). The stage-specific appearance of these antigens in the male germ cells suggests they play a role in spermatogenesis.

The PRAME protein is a CTA discovered initially in a human melanoma cell line. Early studies in cancer biology found that PRAME was a dominant repressor involved in the retinoic acid receptor (RAR) signaling in melanoma cells (Epping et al. 2005, 2007). Later studies indicated that PRAME was involved in nuclear factor $Y$ (NFY)-mediated transcriptional regulation as a subunit of a Cullin2-based E3 ubiquitin ligase in leukemia cells (Costessi et al. 2011). PRAME is a leucine-rich repeat (LRR) protein that folds into a horseshoe shape. This unique protein conformation provides a structural framework for the formation of protein-protein interactions (Chang et al. 2011). It has been reported that another LRR protein, protein phosphatase 1, regulatory (inhibitor) subunit 7 (PPP1R7), also known as SDS22, interacts with protein phosphatase 1, catalytic subunit, gamma isozyme (PPP1CC), also known as PP1 22 , in bovine caudal epididymal spermatozoa (Huang et al. 2002, Mishra et al. 2003). PP1 $\gamma 2$ is a testis/spermatozoaspecific phosphatase, which is a key component for the regulation of spermatozoal motility and male fertility (Smith et al. 1996, Fardilha et al. 2011).

The role of PRAME during spermatogenesis has not been extensively studied. Our recent work demonstrated that the mouse PRAMEL1, a member of the Prame gene family, was first expressed in the cytoplasm of pachytene spermatocytes in 2-week-old testis, and then translocated to the acrosomal region of round spermatids in 3-week-old testis. Furthermore, we have shown in mature spermatozoa that PRAMEL1 was localized to the anterior AC region of spermatozoa, and was differentially expressed in the flagellum and cytoplasmic droplets (Mistry et al. 2013). Like many other multiple copy CTA genes, PRAME was amplified in eutherian mammals during evolution (Birtle et al. 2005, Chang et al. 2011). In bovine, there are multiple copies of PRAME on chromosome 16, and a single copy on chromosome 17. The latter underwent an autosome-to- $Y$ transposition and amplification resulting in a PRAME Y-linked (PRAMEY) gene subfamily, which is expressed solely in testis (Chang et al. 2011). Phylogenetic analysis indicated that this autosome-to- $Y$ transposition event occurred during evolution only in the bovid lineage (Chang et al. 2011, 2013), suggesting an enhanced role of PRAMEY in bovid spermatogenesis and male fertility. A recent study has indeed confirmed that the copy number variation (CNV) of PRAMEY is associated with testis size and male fertility in cattle underscoring the importance of this protein in male reproduction (Yue et al. 2013).
As the first step to understand the functional role of PRAMEY in spermatogenesis and male fertility in cattle, we characterized the expression and localization of the PRAMEY protein at the cellular and subcellular level in the bovine testis and spermatozoa. We found that PRAMEY is a male germ cell-specific protein that is predominantly localized in several cell organelles. Our results suggest that PRAMEY could be essential for AC biogenesis and spermatogenesis.

\section{Materials and methods}

\section{Testis collection, sperm isolation and protein extraction}

All procedures were approved by the Institutional Animal Care and Use Committee at the Penn State University. Bovine testes were collected from a local farm (Spring Mills, PA, USA) during bull calf castration at the age of 20 days, 4 months and 8 months. A portion of the testis tissue was snap-frozen in liquid nitrogen and stored at $-80^{\circ} \mathrm{C}$ for RNA and protein analysis. The remaining tissue was fixed and embedded in paraffin (see below).

Mature testes with intact tunica and attached epididymis were obtained from bulls $(n>10)$ at a local slaughter house (Nicholas Meat Packing Co., Loganton, PA, USA). The testes were transported to the laboratory in ice-filled coolers and processed within $2 \mathrm{~h}$. The epididymides were briefly washed in ice-cold washing buffer $(120 \mathrm{mM} \mathrm{NaCl}, 10 \mathrm{mM} \mathrm{KCl}, 10 \mathrm{mM}$ Tris- $\mathrm{HCl}$ and supplied with $1 \mathrm{mM}$ PMSF, $1 \mathrm{mM}$ EDTA, $1 \mathrm{mM}$ DTT, $\mathrm{pH}$ 7.4) to remove the blood. The caput and caudal epididymal spermatozoa were isolated in modified phosphate buffered saline (PBS) (containing $137 \mathrm{mM} \mathrm{NaCl}, 2.7 \mathrm{mM} \mathrm{KCl}$, $10 \mathrm{mM}$ phosphate buffer, supplied with $1 \mathrm{mM}$ PMSF, $1 \mathrm{mM}$ EDTA, $1 \mathrm{mM}$ DTT, pH 7.4). The isolated spermatozoa were washed twice in the modified PBS, aliquoted and pelleted (Gwathmey et al. 2003). The sperm pellets were immediately frozen in liquid nitrogen.

The sperm pellets were extracted using different protein extraction buffers, including CelLytic buffer (Sigma, product no. C3228), Pierce IP lysis buffer (Pierce, product no. 87787), ReadyPrep rehydration/sample buffer (BioRad, product no. 163-2106) and Laemmli sample buffer (BioRad, product no. 161-0737). Protease inhibitor cocktail (Thermo, product no. 87785; containing AEBSF, aprotinin, bestatin, E-64, leupeptin, pepstatin A and EDTA) and phosphatase inhibitor cocktail (Thermo, product no. 78420; containing sodium fluoride, sodium orthovanadate, sodium pyrophosphate and $\beta$-glycerophosphate) were used as needed. The protein extraction procedure was modified from Shetty and coworkers (Shetty et al. 2001) as follows: the sperm pellets were removed from $-80^{\circ} \mathrm{C}$ freezer, ice-cold extraction buffer (supplemented with protease inhibitor and phosphatase inhibitor cocktail) was immediately added and the pellet was re-suspended in the extraction buffer. After incubation on ice for $10 \mathrm{~min}$, the lysates were centrifuged for $10 \mathrm{~min}$ at $13,000 \mathrm{~g}, 4^{\circ} \mathrm{C}$. The supernatants were referred to as sperm extracts in this study. Alternatively, when the Laemmli sample buffer was used for the protein extraction, the sperm pellets were heated to $95^{\circ} \mathrm{C}$ 
for 5 min in the Laemmli sample buffer supplemented with 5\% $\beta$-mercaptoethanol.

\section{Antibody production}

A PRAMEY-specific custom antibody was produced by New England Peptide, LLC (Gardner, MA, USA). Two rabbits (New Zealand White-SPF) were injected with a synthetic peptide (CAQAGLKPEQA) as an antigen. The peptide sequence 'AQAGLKPEQA' was unique within PRAMEY (amino acid 167176, accession no. GU144302.1); the terminal cysteine residue (C) was added in order to facilitate coupling of the peptide to the carrier protein and affinity matrix. The antibody titers were determined by ELISA and the IgG fraction of the antibody was affinity purified. The PP1 $\gamma 2$ and SDS22 antibodies were kindly provided by Dr Srinivasan Vijayaraghavan (Kent State University) and were described previously (Huang et al. 2002).

\section{Gel electrophoresis and Western blot}

For SDS-PAGE, the protein extracts were separated by $8-16 \%$ Precise Tris-Glycine Gel (Thermo, product no. 25268). The gel was electronically transferred to polyvinylidene difluoride (PVDF) membrane (Thermo, product no. 88518), blocked in $5 \%$ nonfat dry milk in tris-buffered saline containing $0.05 \%$ Tween-20 (TBST). After being briefly washed in TBST, the membrane was incubated in the primary antibody $(1.5 \mu \mathrm{g} /$ $\mathrm{mL}$ ) at $4^{\circ} \mathrm{C}$ overnight. The membrane was washed three times for $5 \mathrm{~min}$ each and incubated in donkey anti-rabbit IgG-HRP (Santa Cruz, product no. sc-2313, 1:5000 dilution) for $1 \mathrm{~h}$. The reactive proteins were detected by SuperSignal West Femto Maximum Sensitivity Substrate (Thermo, product no. 34094). To prove the antibody specificity, pre-absorption of the antiPRAMEY was conducted by incubating the antibody with 200fold excess of its respective synthetic peptide prior to addition to the blots for $1 \mathrm{~h}$ at room temperature (RT). The pre-absorbed antibody or pre-immune rabbit IgG (Thermo, product no. NC-100-P0) was used to replace the primary antibody as a negative control.

\section{Immunofluorescence}

The testicular tissues were cut into small cubes $(3 \mathrm{~mm} \times 3 \mathrm{~mm} \times 3 \mathrm{~mm})$ and fixed in Bouin solution (RICCA chemical company, product no. R1120000-1A 1120-32) for $20 \mathrm{~h}$ at $4{ }^{\circ} \mathrm{C}$. The fixed tissues were dehydrated in $30 \%$ ethanol for $2 \mathrm{~h}, 50 \%$ ethanol for $2 \mathrm{~h}$ and $70 \%$ ethanol overnight. Following several changes of $70 \%$ ethanol, the tissues were embedded in paraffin and cut to $4 \mu \mathrm{m}$ fine sections. The staining procedure was described previously (Mistry et al. 2013). Following deparaffinization and rehydration, the sections underwent heat-induced antigen retrieval by heating to $100^{\circ} \mathrm{C}$ in sodium citrate buffer $(10 \mathrm{mM}$ sodium citrate, $0.05 \%$ Tween 20, $\mathrm{pH}$ 6.0) for $10 \mathrm{~min}$. The sections were washed in PBS and then blocked in $10 \%$ donkey serum in PBS for $1 \mathrm{~h}$ at RT, and incubated with anti-PRAMEY $(1.5 \mu \mathrm{g} / \mathrm{mL}$, in $0.1 \%$ Triton X-100 in PBS) overnight at $4{ }^{\circ} \mathrm{C}$. Following a wash step $(3 \times 5 \mathrm{~min}$ in PBS), sections were incubated with FITC-conjugated donkey anti-rabbit IgG (Santa Cruz, product no. sc-2090, 1:300 dilution) at RT for $1 \mathrm{~h}$, washed again and mounted with VECTASHIELD Mounting Medium with DAPI (Vector, product no. H-1200), and examined on an Olympus BX51 fluorescence microscope with DP Controller image software (Olympus America). For the negative control, the primary antibody was replaced with normal rabbit IgG.

Spermatids and spermatozoa were isolated by cutting and squeezing the testis and epididymis in PBS. The spermatids and spermatozoa were fixed in $4 \%$ paraformaldehyde on ice for $30 \mathrm{~min}$. The fixed spermatids and spermatozoa were washed three times in PBS, placed on slides and allowed to air dry. For immunofluorescence (IF), the sperm slides were rehydrated by PBS, blocked in $10 \%$ donkey serum for $1 \mathrm{~h}$ at RT. After washing with PBS, the slides were incubated with the anti-PRAMEY $\left(1.5 \mu \mathrm{g} / \mathrm{mL}\right.$ in $0.1 \%$ Triton $\mathrm{X}-100$ in PBS) overnight at $4{ }^{\circ} \mathrm{C}$, washed twice in PBS, and incubated in donkey anti-rabbit IgG-FITC (Santa Cruz, product no. sc-2090, 1:300 dilution) for $1 \mathrm{~h}$ at RT. The slides were washed twice in PBS, mounted with VECTASHIELD Mounting Medium and examined on an Olympus BX51 fluorescence microscope as described above. For the negative control, the primary antibody was replaced with normal rabbit IgG.

Three groups of spermatozoa isolated from testis, caput and caudal epididymis, respectively, were used for IF. The staining patterns of the anti-PRAMEY were examined under the fluorescence microscope for approximately 200 spermatozoa randomly selected from each group of spermatozoa. Percentages of spermatozoa with a unique PRAMEY staining in the sperm head and flagellum were calculated and compared among groups.

\section{Immunogold electron microscopy}

The testis tissue and caudal epididymal sperm were processed by the method of cryofixation and Lowicryl embedding (Maunsbach \& Afzelius 1998). The testis tissue and sperm pellet were fixed with $4 \%$ paraformaldehyde and $0.1 \%$ glutaraldehyde for $1 \mathrm{~h}$ at RT, and changed to fresh fixative for another $1 \mathrm{~h}$ at $4^{\circ} \mathrm{C}$. The fixed sperm pellets were pre-embedded in agarose gel. The tissue and sperm pellets were cut into small blocks ( $<0.5 \mathrm{~mm}$ in any direction), completely infiltrated with $2.3 \mathrm{M}$ sucrose at $4^{\circ} \mathrm{C}$ for overnight, and cryofixed in liquid nitrogen. Great care was taken to prevent warming the specimen following this step. The freeze-substitution was performed in the automatic freeze substitution system (Leica Microsystems). The frozen samples were transferred to $0.5 \%$ uranyl acetate in methanol that was kept at $-90^{\circ} \mathrm{C}$ in the freeze-substitution unit. Five hours later, most of the solution was withdrawn and fresh methanol $/ 0.5 \%$ uranyl acetate solution was added. The temperature was raised to $-80^{\circ} \mathrm{C}$ for $24 \mathrm{~h}$. The specimens were then rinsed three times with pure methanol at $-70^{\circ} \mathrm{C}$ over a period of $4 \mathrm{~h}$, and three times with pure methanol at $-45^{\circ} \mathrm{C}$ over a period of $28 \mathrm{~h}$. The samples were infiltrated at $45^{\circ} \mathrm{C}$, with 1:1 mixture of methanol and Lowicryl HM20 (Electron Microscopy Sciences, Hatfield, PA, USA) for $6 \mathrm{~h}, 1: 2$ mixture of methanol and Lowicryl HM20 for $14 \mathrm{~h}$, pure Lowicryl HM20 for $8 \mathrm{~h}$ with three changes, and pure Lowicryl HM20 for $24 \mathrm{~h}$. The samples were changed to fresh Lowicryl HM20 and polymerized with indirect UV light at $-45^{\circ} \mathrm{C}$ for $48 \mathrm{~h}$ and $0^{\circ} \mathrm{C}$ 
for another $24 \mathrm{~h}$. After complete polymerization, the specimen was taken to RT and sectioned to $90 \mathrm{~nm}$ ultrathin sections using conventional ultramicrotomy followed by placing on a nickel grid for examination. For immunogold labeling, the sections were blocked by $1 \%$ BSA in PBS for $30 \mathrm{~min}$, labeled with anti-PRAMEY $(1.5 \mu \mathrm{g} / \mathrm{mL})$ and $10 \mathrm{~nm}$ or $5 \mathrm{~nm}$ gold-conjugated goat anti-rabbit IgG (Ted Pella, product no. 15726 or 15725 , 1:50 dilution). These sections were stained with $2 \%$ uranyl acetate and examined by transmission electron microscopy (FEl Tecnai G2 Spirit BioTwin, at Microscopy and Cytometry Facility, Huck Institutes of the Life Sciences, the Pennsylvania State University, USA). For the negative control, the primary antibody was replaced with the pre-immune rabbit IgG. The classification of the spermatogenic cells during the analysis of the Immunogold electron microscopic (IEM) images was based on the 14 steps of spermatid development described by Berndston and Desjardins (1974).

\section{Co-immunoprecipitation (Co-IP)}

The co-immunoprecipitation (Co-IP) was performed using Pierce Crosslink Immunoprecipitation Kit (Thermo, product no. 26147) as per the instructions. Briefly, the anti-PP1 $\gamma 2$ or anti-PRAMEY antibody was bound to protein A/G plus agarose bead; the bonds between antibody and protein $A / G$ were cross-linked by disuccinimidyl suberate. The caput and caudal epididymal sperm pellets were extracted using IP lysis buffer as described above. The protein extracts were pre-cleared by Pierce control agarose resin, and then incubated with antiPP1 $\gamma 2$ or anti-PRAMEY immobilized agarose beads in minispin columns overnight at $4^{\circ} \mathrm{C}$. The antigen (protein complex) was eluted from the beads by the elution buffer (Thermo, product no. 21004). The input sample (total protein extracts) and the IP/Co-IP eluate were separated by SDS-PAGE and immunoblotted by anti-PP1 $\gamma 2$, anti-PRAMEY or anti-SDS22.

\section{Generation of a recombinant bovine PRAMEY protein}

A recombinant bovine PRAMEY protein was produced by the Novoprotein Scientific Inc. (Summit, NJ, USA) using the human embryonic kidney 293 (HEK 293) system. Briefly, the cDNA sequence (accession no. GU144302.1) that codes for the bovine PRAMEY protein was synthesized and cloned into the pCDNA3.1(-) expression vector. A C-terminal His6 tag was added to the construct, which was confirmed by sequencing. For the HEK293 cell transfection, $100 \mu \mathrm{g}$ pCDNA3.1(-)PRAMEY plasmid in $3 \mathrm{~mL}$ HEK293 free serum-free media was premixed with $400 \mu \mathrm{g}$ polyethylenimine in $3 \mathrm{~mL}$ HEK293 free SFM, which was added into $100 \mathrm{~mL} \mathrm{HEK} 293$ cells $\left(1.0 \times 10^{6} \mathrm{cell} /\right.$ $\mathrm{mL}$ ). The cells were cultured in $37^{\circ} \mathrm{C}, 8 \% \mathrm{CO}_{2}, 130 \mathrm{rpm}$ shaker for 5 days before harvest. The cultured cells were spun down by centrifuging at $4500 \mathrm{rpm}$ for $15 \mathrm{~min}$ at $10^{\circ} \mathrm{C}$, resuspended in buffer PBS ( $\mathrm{pH} 7.4$ ) and lysed by sonication. The supernatant of cell lysate was obtained by centrifugation at $4{ }^{\circ} \mathrm{C}, 12,000 \mathrm{rpm}$ for $20 \mathrm{~min}$. The recombinant protein contains 517 amino acids with a predicted molecular weight of $58.8 \mathrm{kDa}$, which was verified by Western blot (WB) with anti-His tag monoclonal antibody (Supplementary Fig. 1, see section on supplementary data given at the end of this article).

\section{Results}

\section{Generation and validation of a bovine PRAMEY- specific antibody}

The PRAMEY peptide-specific antibody was produced (see 'Methods' section) and validated by WB. As shown in Fig. 1A (lane 1), the anti-PRAMEY antibody detected a strong immune-reactive band with a molecular weight of $\sim 30 \mathrm{kDa}$ in the adult bovine testis. The specificity of the antibody was confirmed by two different negative controls. One was the PRAMEY peptide pre-absorption. The immune-reactive band was absent after the PRAMEY blocking peptide pre-absorption (Fig. 1A, lane 2). The other negative control was the replacement of the antiPRAMEY antibody with preimmune rabbit IgG, which failed to detect any band (Fig. 1A, lane 3), confirming the specificity of the custom-made PRAMEY antibody.

\section{Expression pattern of PRAMEY in bull testes and spermatozoa by WB}

The expression of the bovine PRAMEY in different developmental stages of the testis was examined by WB. The $30 \mathrm{kDa}$ protein was detected in pubertal (8 months) and adult (2 years) bovine testes, but undetectable in 20 days and 4 months testes (Fig. 1B). In addition, a relatively weak band of $\sim 58 \mathrm{kDa}$ that is the predicted molecular weight for the PRAMEY protein (accession no. GU144302.1) was detected in testes at all ages (Fig. 1B).

In order to interpret the discrepancy between the predicted and the observed molecular weights, a recombinant bovine PRAMEY protein was generated and used as a positive control in WB analysis. Using optimized infra-red detection system (Licor, Odyssey System), the intact PRAMEY protein ( $58 \mathrm{kDa})$ was clearly detected in all four ages of testes, though its expression level is significantly low in comparison with the $30 \mathrm{kDa}$ protein identified in pubertal and adult bull (Fig. 1C). The recombinant PRAMEY protein with a His6 tag displayed an expected band of $58.8 \mathrm{kDa}$ with the antiPRAMEY antibody (Fig. 1C), and an anti-His6 antibody (Supplementary Fig. 1). These results further confirmed that not only is the antibody PRAMEY-specific, but also the $30 \mathrm{kDa}$ protein is an isoform of PRAMEY that is specifically expressed in testes after puberty, suggesting that PRAMEY processing is associated with the onset of puberty and initiation of spermatogenesis in cattle.

Interestingly, the expression pattern of PRAMEY in the caput and caudal epididymal sperm was different from the one observed in testes. As shown in Fig. 1C, three immune-reactive bands were detected by the anti-PRAMEY antibody. Besides the $\sim 30 \mathrm{kDa}$ protein that was detected in the pubertal and adult bull testes, two additional minor bands of $\sim 26 \mathrm{kDa}$ and $\sim 13 \mathrm{kDa}$ were detected in all samples studied $(n=4)$. The intact PRAMEY protein was undetectable in both caput and caudal sperm (Fig. 1C). 


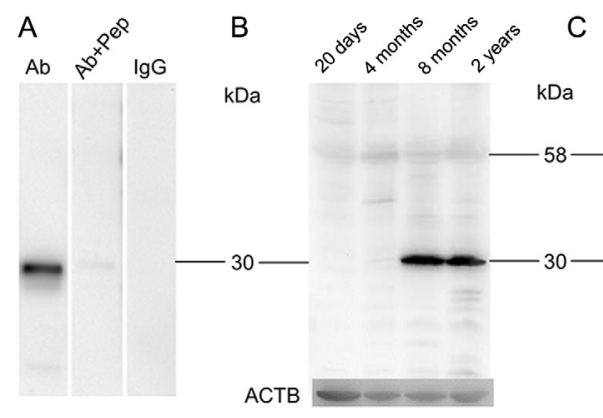

D
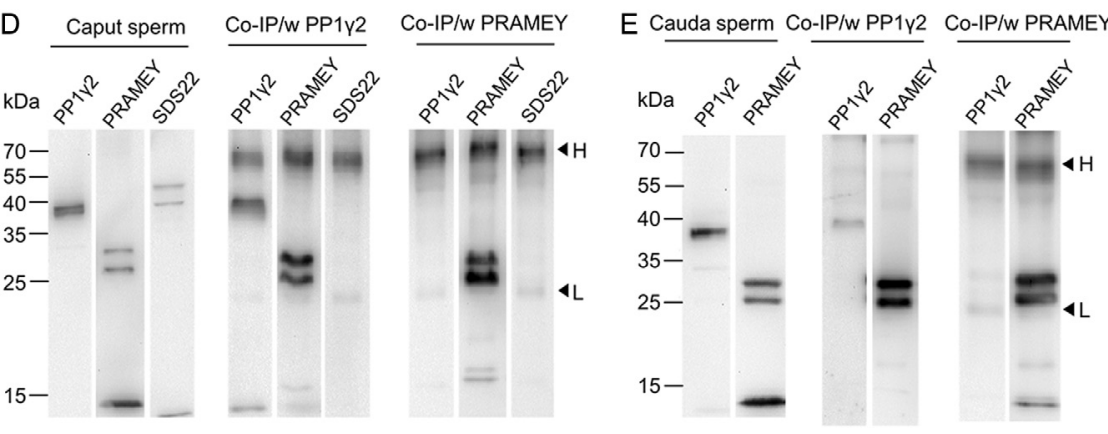

Figure 1 Characterization of the bovine PRAMEY protein in the testis and spermatozoa. (A, B and C) WB analyses with the custom-made anti-PRAMEY antibody. (A) Validation of the anti-PRAMEY-specificity in an adult bull testis. (B and $C$ ) WB results with different ages of bull testis and spermatozoa. The predicted $58 \mathrm{kDa}$ intact protein was detected in different ages of testis, while the $30 \mathrm{kDa}$ isoform was observed only in testes after puberty and epididymal spermatozoa. Two additional bands (26 and $13 \mathrm{kDa}$ ) were detected in the epididymal spermatozoa. Beta-actin (ACTB) was used as a sample loading control. The recombinant PRAMEY protein (RecP) was used as a positive control. ( $D$ and $E$ ) Co-immunoprecipitation (Co-IP) analyses of PP1 $\gamma 2$ with PRAMEY in bovine epididymal spermatozoa. Caput (D) and cauda (E) sperm extracts were incubated with anti-PP1 $\gamma 2$ or anti-PRAMEY. The Co-IP products were immunoblotted by anti-PP1 $\gamma 2$, anti-PRAMEY and anti-SDS22 antibodies. The expected proteins of PP1 $\gamma 2(39 \mathrm{kDa})$ (Huang et al. 2002), PRAMEY and SDS22 (43, 40, $10 \mathrm{kDa})$ (Huang et al. 2002) were observed in the left three lanes (D). Arrow heads on the right mark the bands for the $\lg G$ heavy chain $(\mathrm{H})$ and light chain $(\mathrm{L})$. $\mathrm{Ab}$, antibody;

Pep, PRAMEY peptide; $20 \mathrm{~d}$, 20 days; $4 \mathrm{~m}$, 4 months; 8 m, 8 months; 2 y, 2 years old; kDa, kilo Dalton; $M$, molecular weight ladder protein; RecP, recombinant PRAMEY HEK293 cell lysate.

\section{Interaction of PRAMEY with PP1 $\gamma 2$ in epididymal spermatozoa}

Co-IP analysis was performed with the anti-PP1 $\gamma 2$ or antiPRAMEY antibody on the bovine caput and caudal sperm protein extracts. Both PP1 $\gamma 2$ and PRAMEY were detected in the anti-PP1 $\gamma 2$ Co-IP products (Fig. 1D and E), indicating PP1 $\gamma 2$ and PRAMEY formed a complex in epididymal spermatozoa. However, in the co-IP performed with antiPRAMEY, only PRAMEY was detected (Fig. 1D and E). The anti-SDS22 antibody was used as a negative control in the anti-PP1 $\gamma 2$ co-IP experiments, and no interaction was observed between SDS22 and PP1 $\gamma 2$ in caput sperm (Fig. 1D), confirming a previous report (Mishra et al. 2003).

\section{Localization of PRAMEY in the acrosomal region of spermatids by IF}

The localization of PRAMEY was examined in a crosssection of seminiferous tubules from the testis of adult bulls by IF (Supplementary Fig. 2). The PRAMEY staining covered approximately half of the nuclear surface in round spermatids, and formed a cap-like structure (Berndston \& Desjardins 1974, Clermont et al. 1993) in the perinuclear region; specifically, the AG was strongly stained (Supplementary Fig. 2A, B and C). In elongated spermatids, the PRAMEY staining covered two-thirds of the anterior portion of the nucleus, and also strongly stained the AG (Supplementary Fig. 2E, F and G). Beginning from step 10 of spermiogenesis, the nuclei of elongated spermatids appear flattened when viewed laterally (Supplementary Fig. 2I, J and K). These observations are supported by the earlier description of the cycle of the seminiferous epithelium in the bovine testis (Berndston \& Desjardins 1974). To obtain a more detailed staining pattern, spermatids were isolated from squashed seminiferous tubules, which provided a better view of step 6 (Fig. 2A, a), step 8 (Fig. 2A, b) and step 10 (Fig. 2A, c) spermatids (Berndston \& Desjardins 1974). The results clearly show that the PRAMEY proteins were primarily localized in the AG and the head cap along the development of the acrosomal matrix (AM) and/or acrosomal vesicle (AV). PRAMEY was localized evenly through the entire acrosomal region in step 14 spermatids (Supplementary Fig. 2M, N and O). No fluorescence was observed when the anti-PRAMEY antibody was replaced with pre-immune rabbit IgG (Supplementary Fig. 2D, H, $\mathrm{L}, \mathrm{P})$, indicating that non-specific staining was minimal. 


\section{Localization of PRAMEY in acrosome and flagellum of spermatozoa by IF}

IF with the anti-PRAMEY antibody revealed a similar staining pattern among testicular, caput and caudal spermatozoa (Fig. 2B and Supplementary Fig. 3). PRAMEY was localized in the AC, and/or around the equatorial segment-postacrosomal sheath (ES-PAS) junction in the sperm head, and in the middle and principal piece of the flagellum (Fig. 2B, a, b and c). No staining was observed in the negative controls when the primary antibody was replaced by either the pre-immune rabbit IgG or the antibody dilution buffer (without the primary antibody) (Fig. 2B, d and Supplementary Fig. 3). To further study the three different localization patterns, i.e. 'AC', 'AC\&ES-PAS', 'ES-PAS', in the sperm head, over 200 spermatozoa were examined from each group (Table 1). The results revealed that the percentage of the three localization patterns differed among testicular, caput and caudal spermatozoa. The percentage of 'AC' immunostained sperm decreased with the maturation of spermatozoa from $87.0 \%$ in testicular spermatozoa, to $25.9 \%$ in caput and $7.3 \%$ in caudal epididymal spermatozoa, while the percentages of spermatozoa with 'AC\&ES-PAS' and 'ES-PAS' staining patterns were increased accordingly (Table 1).

\section{Subcellular localization of PRAMEY in spermatogenetic cells and spermatozoa by IEM}

IEM was applied to identify the subcellular location of PRAMEY in the adult testis and epididymal spermatozoa. The PRAMEY immunogold labeling was initially observed in spermatogonia and spermatocytes (Fig. 3), and in all steps of spermatid development (Figs 4, 5, 6, 7 and 8), and in testicular and epididymal spermatozoa (Fig. 8). In general, immunogold particles were clustered as groups in the electron-dense region of the nucleus and the cytoplasm except for the AG, where the immunogold labeling was associated with a previously undescribed structure in the matrix of the AG (Fig. 7). AntiPRAMEY binding sites and the enrichment of the gold particles were primarily observed in a dozen different organelles of the above-mentioned spermatogenic cells (summarized in Fig. 9), which are described in detail below. In contrast, there was very limited nonspecific labeling or no labeling observed in all testicular cells in the negative control (Supplementary Fig. 4).

\section{Nucleus}

Immunogold labeling was observed in clusters in the electron-dense region of the nucleus in spermatogonia (Fig. 3A and $\mathrm{B}$ ) and spermatocytes (Figs $3 \mathrm{D}$ and $6 \mathrm{~A}, \mathrm{C}$ ), and in steps 1-14 of spermatid development (Figs 5, 6, 7 and 8). The PRAMEY labeling was also clearly observed in the nucleolus of spermatogonia (Fig. 3B). The density
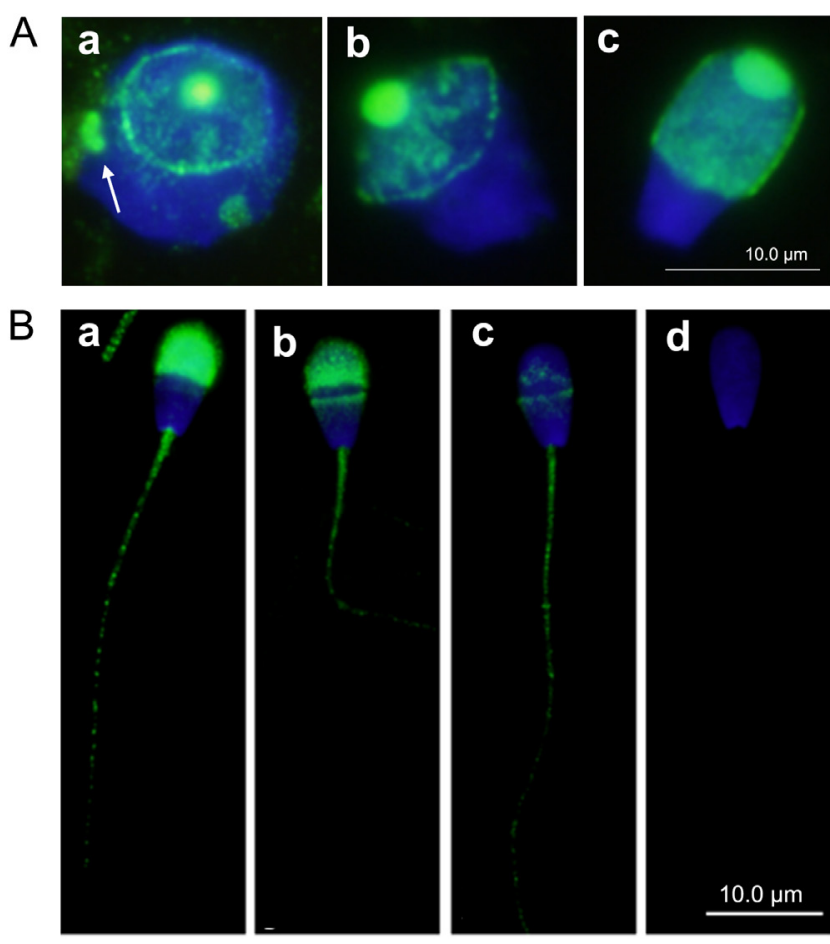

Figure 2 Localization of the bovine PRAMEY during spermatogenesis by IF. (A) Testicular spermatids were isolated and stained with anti-PRAMEY (green) and counterstained with DAPI (blue). The PRAMEY staining was strong in the AG, and light in head cap of step 5 (a), step 7 (b) and step 10 (c) spermatids. A heavily

PRAMEY-labeled chromatoid body (CB) was clearly observed on the left side of the nucleus in the panel (a) (arrow). (B) The bovine caudal epididymal spermatozoa were isolated and stained with antiPRMAEY antibody, and then counterstained with DAPI. The PRAMEY staining was mainly localized in the AC (a), in both AC and PAS junction (b), or in PAS junction (c) in the sperm head. The staining was also observed in the flagellum ( $a, b$ and $c)$. No staining was observed in the pre-immune rabbit IgG negative control (d). Scale bar $=10 \mu \mathrm{m}$.

of the clustered gold particles in the electron-dense region of the nucleus varied with development of spermatogenic cells. Less labeling was observed in the nucleus of spermatogonia (Fig. 3B) and spermatocytes (Fig. 3D) and the early developing spermatids (Figs 5B and $6 \mathrm{C}, \mathrm{D}, \mathrm{E})$, and more labeling was observed in the nucleus of elongating spermatids where the nuclear chromatin was condensing (Figs 7E and 8A, B, C, D, E). The distribution of the clustered labeling within the nucleus of elongating/elongated spermatids was uneven. The highest density of the labeling was observed in the region associated with the perinuclear ring (PNR) (Fig. 8A, B and C). Clusters of labeling were observed in at least two regions of nuclear envelope in the elongating spermatids: one region was where the nuclear envelope contacts with AC (Fig. 7D) and the other was the PNR region (Fig. 8C; see below). There was limited labeling in the nucleus of epididymal spermatozoa (Fig. 7F). 
Table 1 The bovine PRAMEY antibody staining in spermatozoa isolated from testis, caput and caudal epididymis.

\begin{tabular}{lccccc}
\hline Sperm location & No. of sperm & AC $(\%)$ & AC and ES-PAS (\%) & ES-PAS (\%) & Unstained (\%) \\
\hline Testis & 123 & 82.9 & 13.0 & 4.1 & 0.0 \\
Caput epididymis & 264 & 25.9 & 49.4 & 20.0 & 4.7 \\
Caudal epididymis & 259 & 7.3 & 60.6 & 27.4 & 4.7 \\
\hline
\end{tabular}

AC, acrosome; ES-PAS, equatorial segment-postacrosomal sheath junction.

\section{Endoplasmic reticulum (ER) and vesicles}

In addition to the nucleus, the PRAMEY labeling was observed in small electron-dense particles in the cytoplasm and in the rough ER of spermatogonia (Fig. 3A, B and C) and spermatocytes (Fig. 3D). There were many small vesicles of variable size present in the cytoplasm of spermatocytes. The majority of the small vesicles did not contain the electron-dense materials. However, a small portion of the small vesicles contained the electron-dense materials, and clusters of immunogold labeling were clearly observed in the electron-dense regions of the vesicles (Fig. 3D and E). In the Golgi phase of spermiogenesis, some of these PRAMEY-labeled small vesicles appear to fused with a large non-electron-dense vesicle, i.e. AV, which resided close to the anterior nucleus (Fig. 3F). The PRAMEYlabeled electron-dense materials in small vesicles may provide the initial materials for the establishment of the AG (Figs 3E, F and 10A).

\section{Intermitochondrial cement (IMC)}

Multiple IMCs were found in the cytoplasm of spermatocytes with heavy immunogold labeling in clusters in the cement portion (electron-dense region) of IMCs (Fig. 4). The number of mitochondria aggregated in IMCs varied dramatically from two to more than six (Fig. 4). Occasionally, light labeling was observed in some mitochondria within IMCs (Fig. 4B and C). Since no labeling was seen in the mitochondria that were not aggregated to IMCs, we tend to believe that the light labeling on IMC-aggregated mitochondria was likely from the IMC cement materials that were located very close to the section position. In addition to the typical IMCs (Fig. 4A, B and C), we observed some gradually disassembled, non-typical IMCs (Fig. 4D), in which the cement materials started to transform into a chromatoid body (CB)-like structure, while some mitochondria remained in contact (or were clustered) with the IMC/CB structure (Figs 4D and 5A). Therefore, the non-typical IMC represents a transitional stage from IMC to CB.

\section{Chromatoid body}

Intensive immunogold labeling of PRAMEY was observed in clusters predominantly in CBs of round (Fig. 5A, B, C and D) and elongating spermatids (Fig. 5E, F and G). In early round spermatids (steps 1-3), two distinct types of CBs were observed based on the shape of CBs. Type I CBs were usually large $(\geq 2 \mu \mathrm{m})$, cloud-like in a loose network without membrane, variably shaped, with or without contact with the mitochondria (Fig. 5A and B). Frequently, there was only one type I CB observed in round spermatids, which was often seen in contact with the nucleus (Fig. 5E). Type II CBs had a large, round honeycomb-like structure $(1-2 \mu \mathrm{m})$ without contact with the mitochondria (Fig. 5C and D). Our data clearly
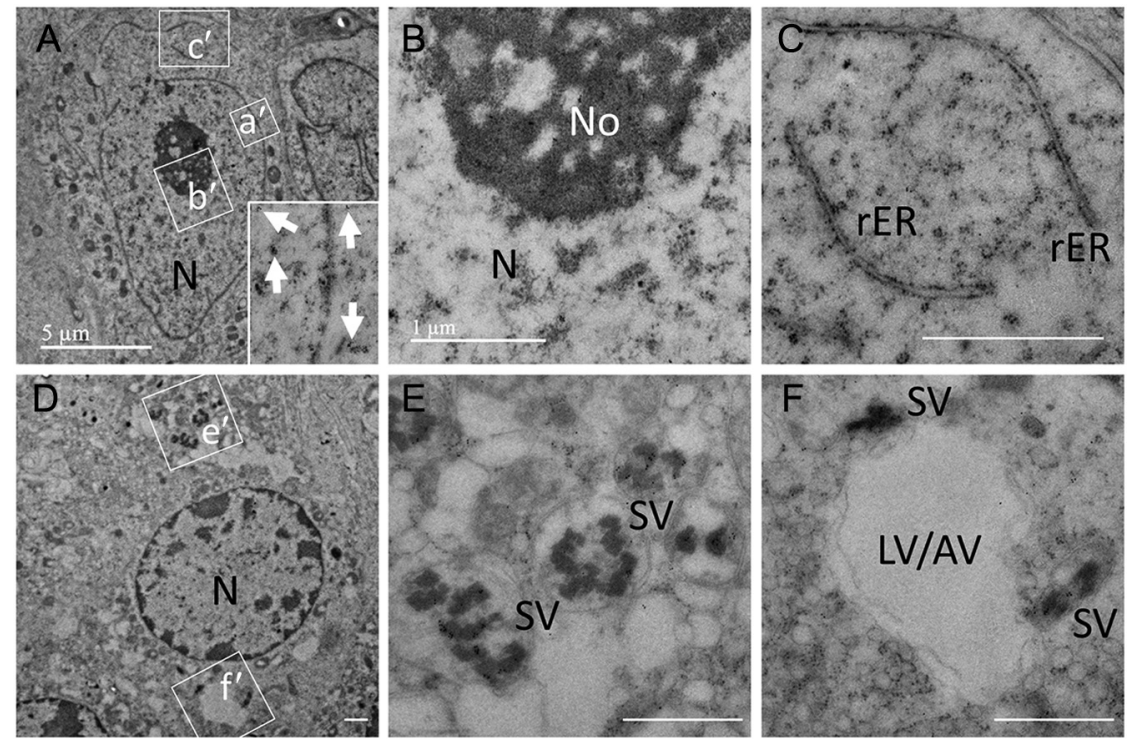

Figure 3 Subcellular localization of the bovine PRAMEY in spermatogonia and spermatocytes by IEM. (A) A spermatogonia from an adult bull testis. Immunogold particles of PRAMEY were observed in clusters in the electrondense materials of cytoplasm and the nucleolus. The insert was an enlarged area from box $\mathrm{a}^{\prime}$ where the PRAMEY labeling was clearly observed (arrow). (B and C) Enlarged regions of the nucleus $(\mathrm{N})$ and nucleolus $(\mathrm{No})$ from box b', and a region of the cytoplasm with rough $E R(r E R)$ from box $c^{\prime}$ in the panel (A). (D) A late spermatocyte from the testis of the same bull in the panel (A). (E and F) An enlarged region from boxes $e^{\prime}$ and $\mathrm{f}^{\prime}$ showing the intense clustered PRAMEY labeling in the electron-dense materials of small vesicles (SV), which are fused with the large (or acrosomal) vesicle (LV/AV) in the cytoplasm. Scale bar $=1$ or $5 \mu \mathrm{m}$. 

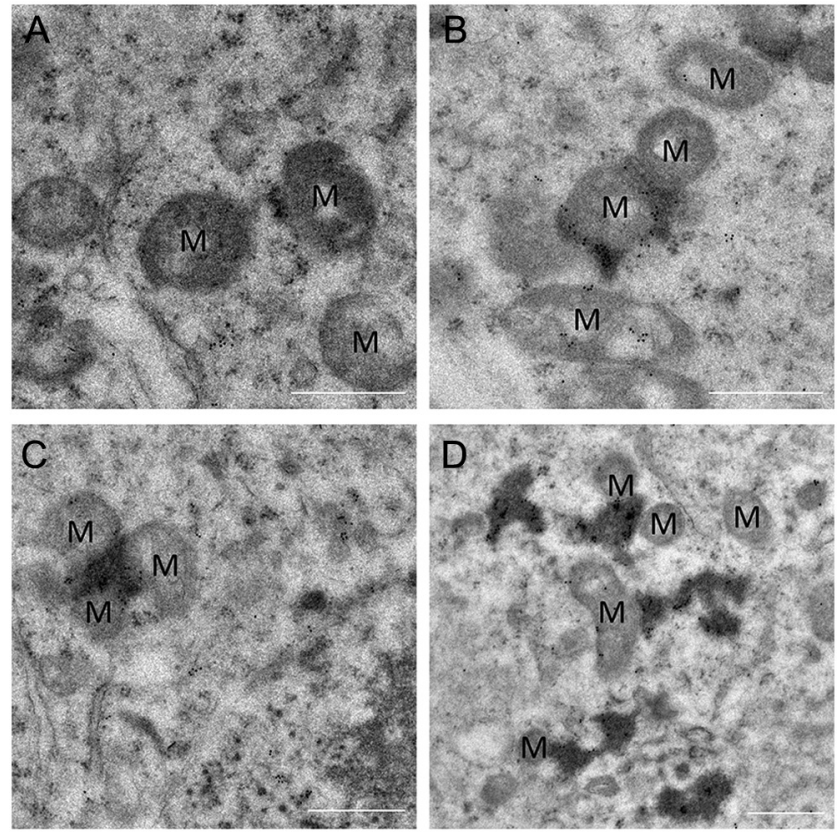

Figure 4 Localization of the bovine PRAMEY in the IMC by IEM. (A) Mitochondria (M) began to aggregate around the electron-dense material to form IMC in pachytene spermatocytes. (B and C) Typical IMC with clustered-labeling of PRAMEY in the cement part of IMC in pachytene spermatocytes. (D) The typical IMC structure began to disassemble by disassociation of the mitochondria from the electrondense materials and by the formation of chromatoid body-like structure in an early round spermatid. Scale bar $=0.5$ or $1 \mu \mathrm{m}$.

showed that the formation of the type II CB started with a small satellite-like body (Sud 1961) (Fig. 5B), which expanded during the development of round spermatids. The mature size of the type II CB was equal to or even larger than the type I CB (Fig. 5C and D). Compared to type I, the type II CBs were relatively light in their electron density, although the PRAMEY labeling level was similar (Fig. 5B, C and D). No specific labeling was observed in the non-electron dense part of the type I and II CBs. Since the two types of CBs were always located adjacent to or in contact with each other (Fig. 5B, C and D), we believe that both types of CBs may be essential for the development of the early round spermatids (steps $1-3)$ in cattle.

In the late round spermatids and elongating spermatids (steps 4-9), only the type I CB was observed (Fig. 5E) with heavy immunogold labeling similar to the one detected in the early round spermatids. In the cap phase of spermiogenesis, a single type I CB was frequently observed nearby the AV adjacent to the anterior nucleus, whereas during the acrosomal phase this heavily labeled $\mathrm{CB}$ migrated to the distal region where the two centrioles were located and the flagellum developed (Fig. 6D).

Along with the disappearance of the typical type I CB structure in the elongated spermatids (steps 10-14), we observed three additional germinal granule-likestructures with PRAMEY labeling. The first one was known as the late CB (Susi \& Clermont 1970, Onohara et al. 2010), surrounded by clear vesicles (Figs $5 \mathrm{~F}, \mathrm{H}$ and $8 \mathrm{~A}, \mathrm{~B}$ ). The second one was called mitochondria-attached granule (MAG)-like granule (Onohara et al. 2010), surrounded by mitochondria (Fig. 5G). Both late CB and MAG-like structures were heavily labeled by PRAMEY, located in the cytoplasm, similar in size $(\sim 0.5 \mu \mathrm{m})$ and consisted of a large mass of granular material. The third granule was an IMC-like structure located on the flagellum during the formation of the mitochondrial sheath (Fig. 8F). The gold particles were observed in the cement-like electrondense materials that aggregated the mitochondria (Fig. 8F), suggesting that PRAMEY may be involved in the assembly of the mitochondrial sheath.

\section{Centrioles and annulus}

Centrioles that had not migrated to the distal end of the nucleus in early steps (steps $1-5$ ) of spermatids had either no labeling or a very light labeling in the outside of the microtubule doublets (Fig. 6A and B). Clusters of labeling were observed essentially in the microtubules of both the proximal and the distal centrioles that had migrated to the distal side of the nucleus in the cytoplasm of step 6 round spermatids, and that had either pro-attached or attached to the nuclear envelope (Fig. 6C, D, E and F). As the heavily labeled CB was frequently observed in contact with or nearby the centrioles in the posterior nucleus, we reason that the CB provides the PRAMEY-associated protein complex to the centrioles during their migration towards the posterior nucleus.

During the attachment of the proximal centriole to the nuclear envelope of round spermatids, the nuclear envelope curved back to form an implantation socket (IS). Dense clusters of immunogold particles of PRAMEY were observed in the pericentriolar material located between the proximal centriole and the newly formed IS (Fig. 6D). Intense labeling was also localized in microtubules of the distal centriole in steps 7-8 spermatids when they began elongation to become the flagellum of the spermatozoon (Fig. 6E). Annulus was visible in these spermatids, and limited labeling was observed in the annulus structure. However, more intense labeling was observed in the annulus of step 9 (Fig. 6F) and step 13 spermatids (Fig. 8D), indicating the distribution and amount of the PRAMEY-associated protein complex were gradually increased along the development of the flagellum.

\section{Acrosomal granule}

In the cap phase, an intense labeling was observed in the single, prominent, centrally located AG in step 3 spermatids (Fig. 7A) when AG had just emerged from the Golgi vesicle. The latter had not extended over the anterior nuclear surface (Fig. 7A and B). The dense 

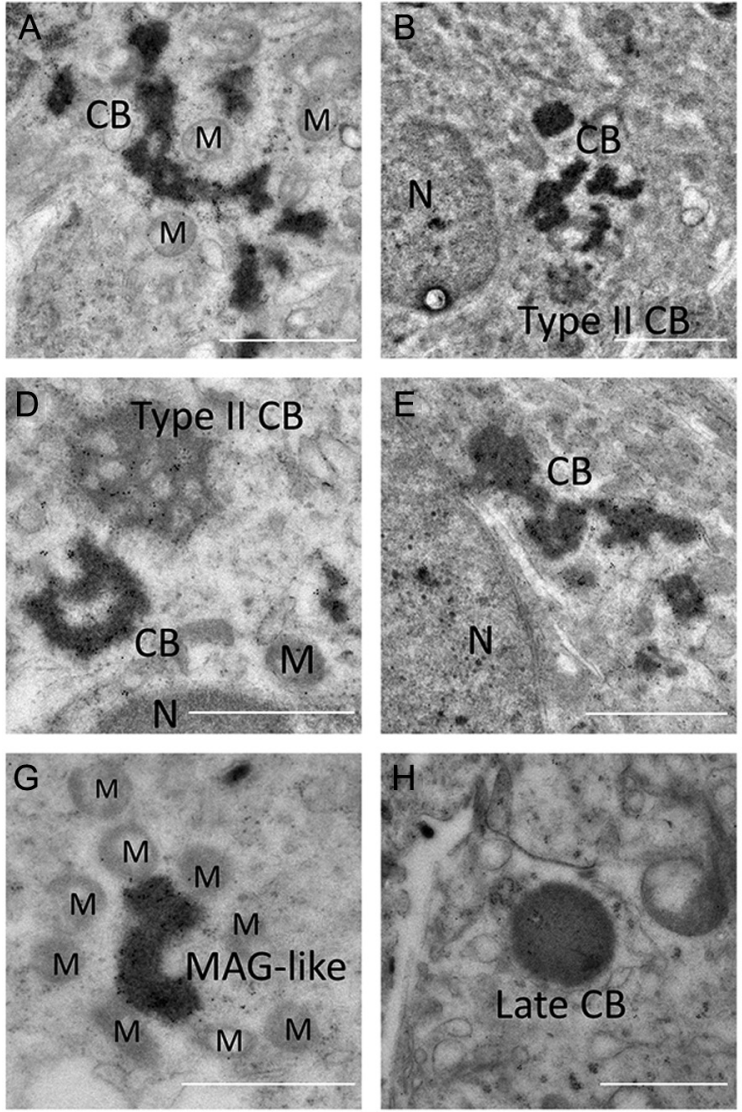
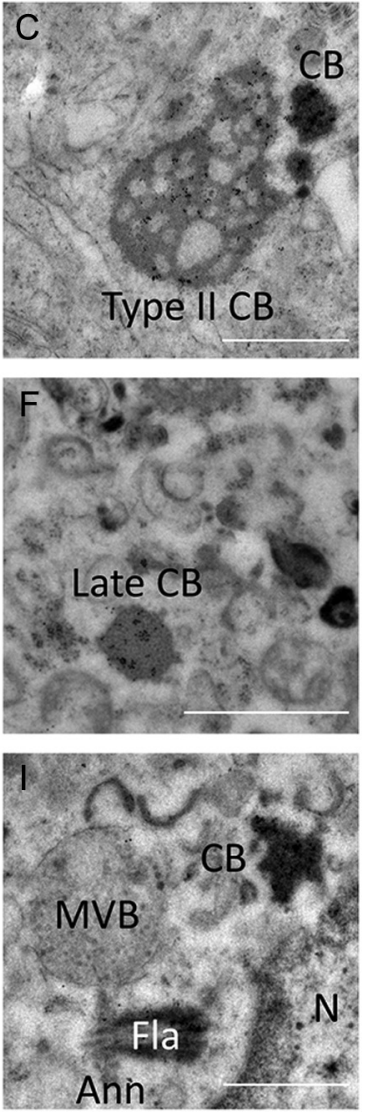

Figure 5 Localization of the bovine PRAMEY in the CB of spermatids by IEM. (A, B, C, D and $\mathrm{E}$ ) Clustered labeling of PRAMEY were observed in the electron-dense materials of the type I and type II CBs in early spermatids. (A) A type I CB in step I spermatid. (B) A typical type I and a newly formed type II CB in step 2 spermatid. (C and D) Type I and II CB in step 3 (C) and step 4 spermatid (D). (E) A type I CB in step 6 spermatid. (F) A late CB in the residual body of step 13 spermatid. (G) $A$ MAG-like granule in the residual body of step 14 spermatid. (H) A late CB in step 14 spermatid. (I) No labeling was found in a multivesicular body (MVB) (as negative control) of step 6 spermatid. In contrast, a heavily labeled type I CB and an early stage of developing flagellum (Fla) were present in the vicinity. Scale bar $=1 \mu \mathrm{m}$. immunogold particles were observed exclusively in the granule, not in the AV region in the early spermatids (steps 3-4) (Fig. 7A and B). With the development of spermatids and the formation of $\mathrm{AC}$, immunogold labeling was enriched in the AG, and was observed occasionally in a very low density outside of the granule in the AV region (Fig. 7B). The distribution of the gold particles in the AG was neither random nor clustered in groups (Fig. 7C) as observed in other cell organelles. The gold particles were well-organized in a 'string of beads' pattern on a filamentous material, which appears to represent a structural element within the AG matrix (Fig. 7C) that has not been described in literature. This AG matrix network was observed when the AG was formed (Fig. 7A), and
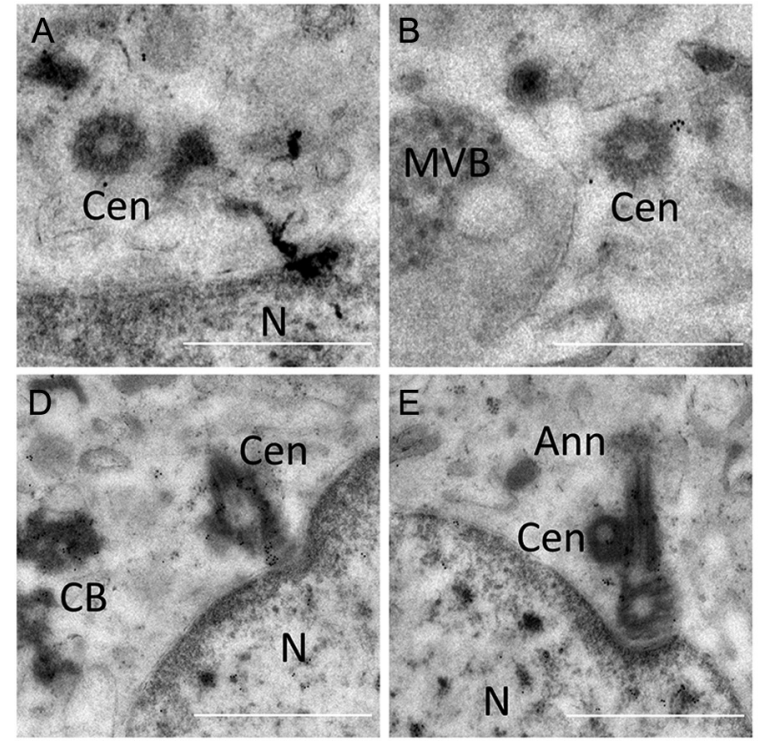
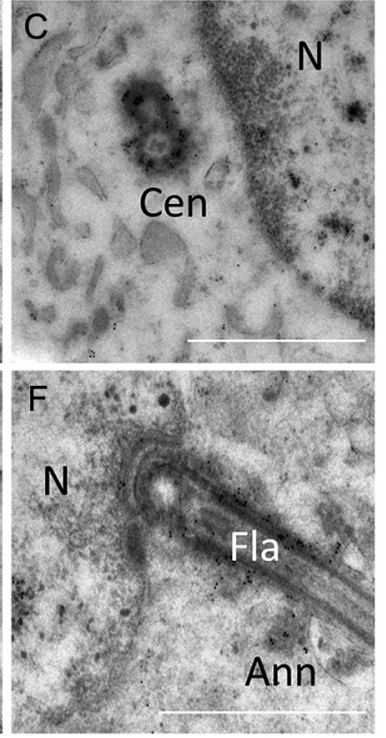

Figure 6 Localization of the bovine PRAMEY in centrioles and the flagellum of spermatids by IEM. (A and B) A centriole (Cen) with no PRAMEY labeling in step 5 spermatid. (C) A pair of centrioles with labeling in step 6 spermatid. (D) The centrioles began to interact with the nucleus in step 6-7 spermatid. (E) The initiation of the sperm neck and flagellum with the proximal and distal centrioles in step 7 spermatid. (F) The development of the sperm neck and flagellum (Fla) in step 9 spermatid. PRAMEY labeling was observed in clusters in the nucleus $(N)$ of all spermatids presented in panels A, B, C, D, E and F. Scale bar $=1 \mu \mathrm{m}$. 


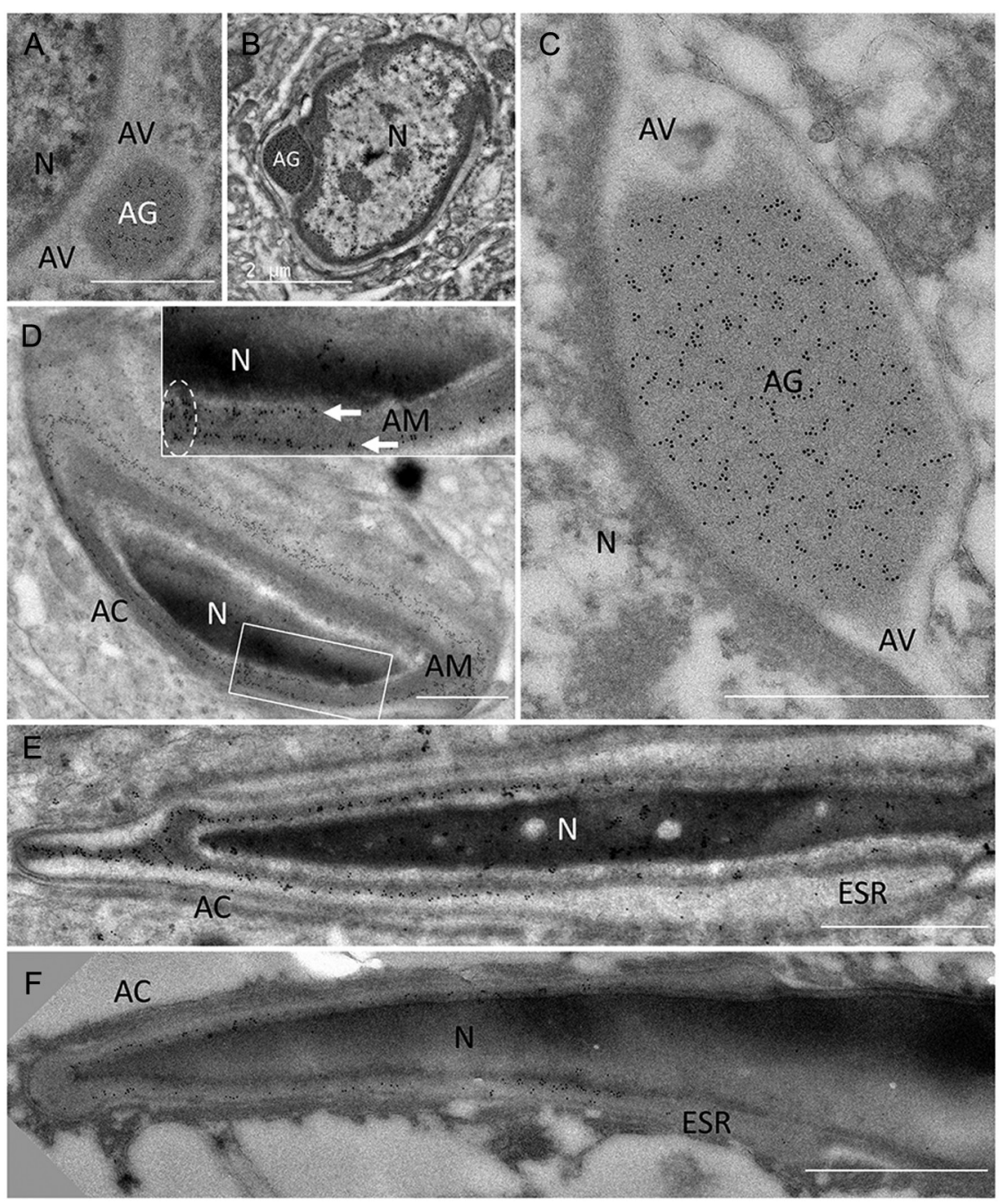

Figure 7 Localization of the bovine PRAMEY in the acrosomal granule (AG) and matrix (AM) by IEM. (A, B and C) Localization of PRAMEY in the AG of early spermatids in the cap phase. (A) A newly formed AG in step 3 spermatid. (B) An expended AG in step 5 spermatid. (C) An enlarged AG in step 6 spermatid. The immunogold particles organized in the 'string of beads' pattern were clearly observed. (D and E) Localization of PRAMEY in the acrosomal matrix (AM) and the nucleus $(\mathrm{N})$ of the elongating spermatids. (D) A cross-section from the acrosome (AC) and the proximal end of an elongating nucleus $(\mathrm{N})$. The insert in $\mathrm{D}$ was an enlarged image from the boxed region where two layers of immunogold particles were occasionally present (arrows). There was an unknown structure in the center of this region with heavy labeling that may interact with the nucleus (dashed-line circle). (E) A longitudinal section of the developing acrosome in step $10 \mathrm{~nm}$ spermatid. (F) Localization of PRAMEY in the AM of cauda epididymal spermatozoa. Panels A, D and $\mathrm{F}$ were labeled by $5 \mathrm{~nm}$ gold particles, while panels B, C and E were labeled by $10 \mathrm{~h}$ gold particles. Scale bar $=1$ or $2 \mu \mathrm{m}$. expanded with development of the granule in the cap phase. The network remained during flattening of the AV and the AG during the acrosomal phase (Fig. 7D). It disappeared during the maturation phase when the AG flattened and became the AM (Fig. 7E and F).

\section{Acrosome and equatorial segment (ES)}

Upon elongation of spermatids, AG flattened within the AV and became the AM. PRAMEY labeling was localized in the AM in steps 6-14 spermatids (Fig. 7A, B, C, D and $\mathrm{E})$ and in the caput and cauda epididymal spermatozoa (Fig. 7F). During the formation of the AC and ES in steps 11-14 spermatids, heavy labeling was observed in the proximal region of $\mathrm{AM}$ that is not present in the ES region (ESR), whereas limited or no labeling was observed in the AM of ES (Fig. 7E).

In the mature cauda epididymal spermatozoa, PRAMEY labeling was localized in the matrix of the $A C$, specifically in the peri-inner acrosomal membrane (IAM) region, but did not actually label the IAM (Fig. 7F). Compared to late steps of spermatids (Fig. 7E), the electron-dense region of the $\mathrm{AC}$ was thinner in cauda spermatozoa, although PRAMEY was still localized in the electron-dense region within the AC (Fig. 7F).

\section{Postacrosomal sheath (PAS), perinuclear ring (PNR) and manchette}

Clusters of immunogold particles were also observed in PAS, PNR and the manchette (Fig. 8A, B, C, D and E). During the development of PAS, the PNR gradually moves towards the connecting piece $(\mathrm{CP})$ of the sperm flagellum. Condensed labeling was observed in the lateral section of PNR and the PAS-PNR junction, particularly within the nuclear region surrounded by this junction (Fig. 8A, C and E). More importantly, we observed clusters of heavily labeled gold particles crossing the nuclear envelope at, or close to the PNR, indicating that PRAMEY and its associated proteins are frequently moving across the nuclear membrane at the PAS-PNR junction (Fig. 8C and D). Compared to PNR and the PAS-PNR region, significantly less labeling was observed in the microtubules within the longitudinal section of the manchette (Fig. $8 \mathrm{C}$ and D). The location 

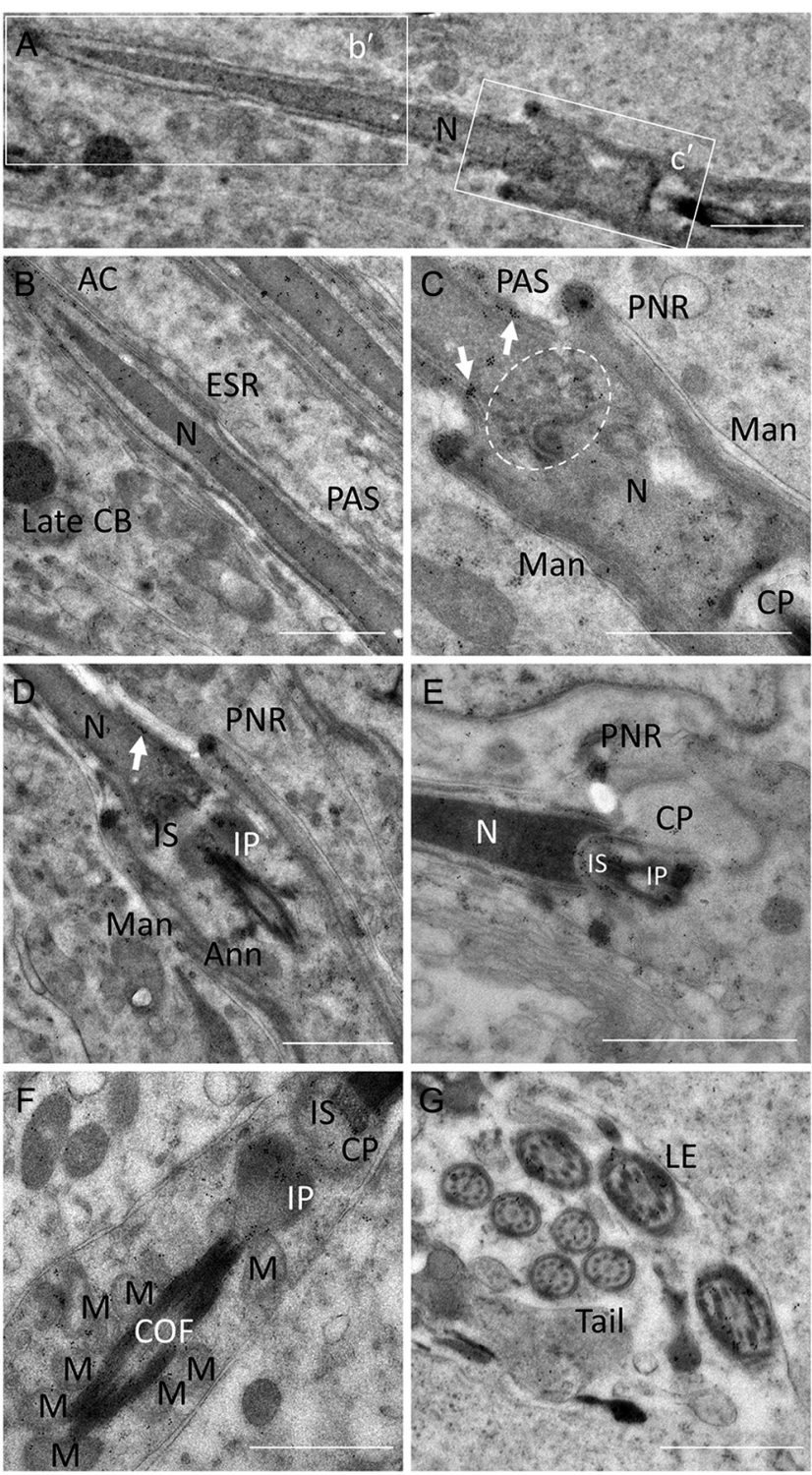

Figure 8 Localization of the bovine PRAMEY in the head of elongated spermatids and the flagellum of epididymal spermatozoa by IEM. (A, B and C) A longitudinal section of the head and connecting piece (CP) of step 11 spermatid. An enlarged region from box $b^{\prime}(B)$ and box $C^{\prime}(C)$ in panel $(A)$ shows the detailed structure and localization of PRAMEY in several organelles including the nucleus $(\mathrm{N})$, developing acrosome $(\mathrm{AC})$, equatorial segment region (ESR), postacrosomal sheath (PAS), perinuclear ring (PNR) and manchette (MAN). (D and E) A longitudinal section of the CP in step 11 spermatid (D) and step 12 spermatid (E), shows, in particular, the implantation socket (IS) and plate (IP) of CP. (F) A longitudinal section of the midpiece of step 13 spermatid. (G) Lateral section of the midpiece and the principal piece of late step spermatids. Clustered labeling was observed primarily in the principal piece, while less (or no) labeling was observed in the axoneme of the flagellum. Arrows in (C) and (D) indicate clusters of immunogold particles located adjacent to the nuclear membrane.

Scale bar $=1 \mu \mathrm{m}$.
A
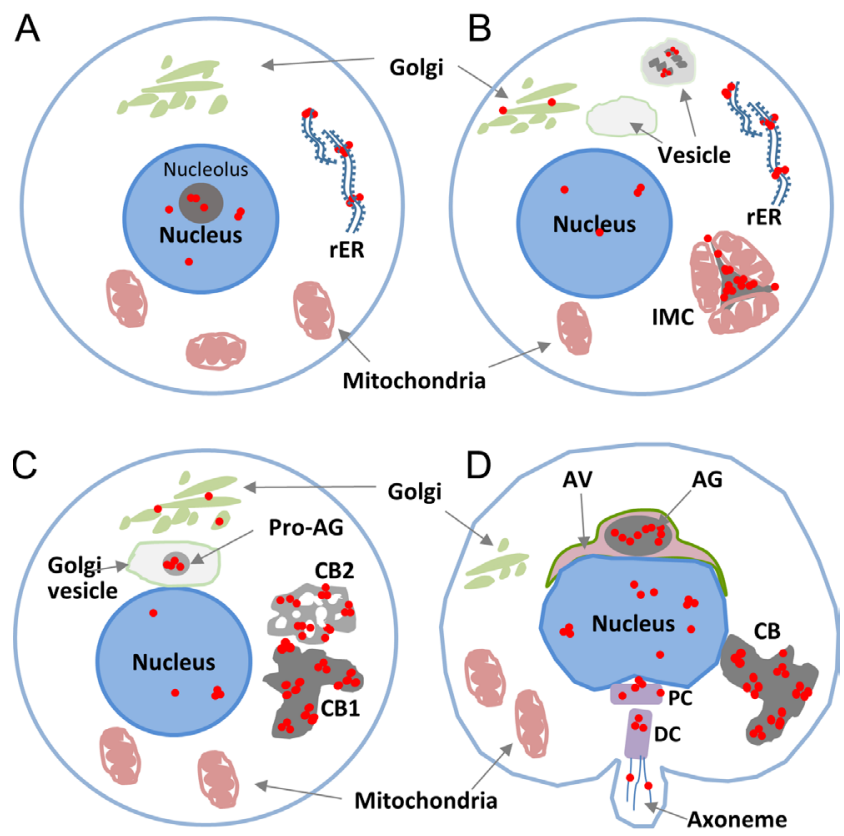

E

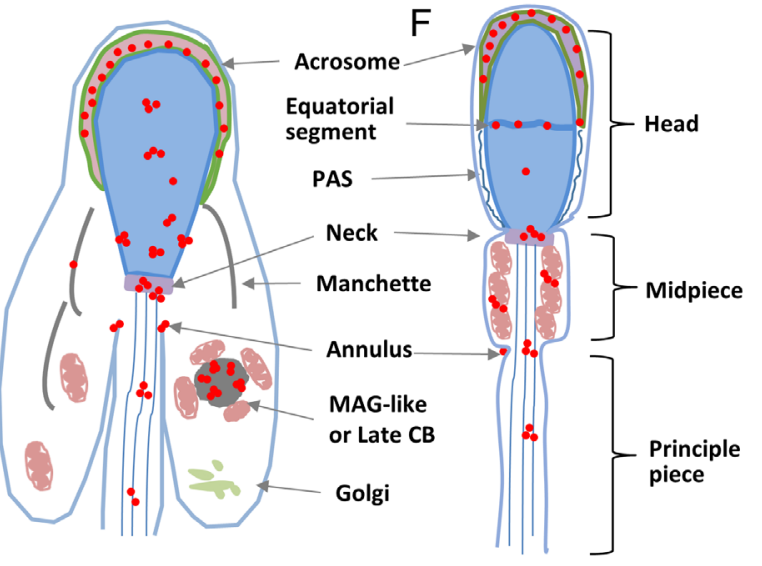

Figure 9 Schematic representation of PRAMEY localization during spermatogenesis in cattle as revealed by IEM. (A) Spermatogonia. (B) Late spermatocytes. (C) Early round spermatids in the Golgi phase. (D) Spermatids in the cap phase. (E) Elongating spermatids in the acrosomal phase. (D) Elongated spermatids in the mature phase. Red dots represent the PRAMEY-labeled immunogold particles.

of the labeling in these microtubules varied from cell to cell based on their developmental stage, suggesting that the PRAMEY-associated protein complex may move along manchette microtubules.

\section{Flagellum}

In the late steps (steps 12-14) of elongated spermatids, intense labeling was observed in both the IS in the posterior head of nucleus and the implantation plate (IP; also known as sperm capitulum) in the CP (Fig. 6D and $8 \mathrm{C}, \mathrm{D}, \mathrm{E}$ and $\mathrm{F}$ ). Clusters of labeling were found in the coarse outer fibers (COF) of the midpiece of the sperm flagellum based on IEM images from lateral and longitudinal sections (Fig. 8F and G). Heavy labeling 
was often associated with the longitudinal elements (LE) in the principal piece of the sperm flagellum (Fig. 8G). However, no labeling was observed in the axoneme of the flagellum (Fig. 8G).

\section{Discussion}

As one of the CTAs and a LRR protein, PRAME has been studied in tumorous cells and was found to function in transcription regulation (Epping et al. 2005, 2007, Costessi et al. 2011). However, the function of PRAME in non-tumorous cells and germ cells is largely unknown. During the male germ cell development in mice, Prame and its paralogs, including Pramel, Pramel1 and Pramel3 were expressed in spermatogenic cells (Mistry et al. 2013). A recent knockout study indicated that the deletion of a $1.1 \mathrm{Mb}$ segment that includes Prame, Pramel, Pramel 3 and 13 additional genes from the mouse $X$ chromosome led to defective chromosomal synapsis, meiotic arrest and sterility in male mice (Zhou et al. 2013). The three genes in the Prame family were likely candidates responsible for the meiotic defects as they are testis-specific (Zhou et al. 2013). In the present study, we demonstrated that, in addition to the nucleus, PRAMEY localizes in several organelles of spermatogenic cells (Fig. 9), indicating that its function is likely beyond the regulation of transcription.

\section{Difference in PRAMEY properties in different developmental stages of bull testis and epididymal spermatozoa}

Two polypeptides (58 and $30 \mathrm{kDa}$ ) were identified in the bovine testes, while three peptides (30, 26 and $13 \mathrm{kDa}$ ) were identified in epididymal spermatozoa with the custom-made PRAMEY-specific antibody. The $58 \mathrm{kDa}$ intact PRAMEY protein was detected at a low level when tested in testis of all ages, whereas it was undetectable in caput and caudal epididymal spermatozoa. The $30 \mathrm{kDa}$ PRAMEY isoform was detected in pubertal (8 months) and adult (2 years) bull testes as well as in epididymal spermatozoa but not in testes before puberty, suggesting that this isoform is particularly involved in spermiogenesis. The remaining two minor bands, 26 and $13 \mathrm{kDa}$, were observed only in epididymal spermatozoa and are discussed below.

\section{An unknown factor specific to epididymal spermatozoa causes the specific cleavage of PRAMEY}

The two minor bands, $26 \mathrm{kDa}$ and $13 \mathrm{kDa}$, specific to the epididymal spermatozoa, were consistently detected in WB analyses with four biological and technical replicates. This observation suggests that there was an unknown biological factor, such as a protease, which is specific to the epididymis that caused the specific cleavage of the $30 \mathrm{kDa}$ PRAMEY isoform. A bioinformatics approach was applied in this study to identify any potential protease that could produce the $26 \mathrm{kDa}$ and $13 \mathrm{kDa}$ bands, and no known protease was identified (unpublished data).

Early studies in guinea pigs identified several acrosomal proteins, such as acrosomal matrix protein 50 (AM50) (Westbrook-Case et al. 1995), acrosin (ACR) (Anakwe et al. 1991), granulin or acrogranin (GRN) (Baba et al. 1993), cysteine-rich secretory protein 2 (CRISP2) (Foster \& Gerton 1996), and acrosomal matrix component 67 (AM67) (Foster et al. 1997), which are modified to a lower molecular weight during epididymal transit and maturation. These modifications were considered as a necessary process for the final remodeling of the AM (Westbrook-Case et al. 1995). Our data evidently indicated that the PRAMEY protein is processed in a similar way as other AM proteins. However, the mechanism underlying the reduction of molecular weight during epididymal transit is still unknown. Investigation on the mouse zona pellucida sperm-binding protein 3 receptor (ZP3R), also known as SP56, or AM67, revealed that the cleavage of ZP3R was processed by proteases coincident with release from the AC during sperm capacitation (Buffone et al. 2009). Another acrosomal protein, acrosomal vesicle protein 1 (ACRV1), also known as SP-10, has several small peptides $(32,30,28$ and $26 \mathrm{kDa})$ in addition to the intact $45 \mathrm{kDa}$ protein (Kurth et al. 1993, Coonrod et al. 1996). Similar to ZP3R, the small peptides of ACRV1 were products of proteolytic processing occurring during the epididymal transit.

\section{Discrepancy in molecular weight between the predicted protein and observed polypeptides in the PRAME/PRAMEY family}

The molecular weight of the predicted intact PRAMEY protein is $58 \mathrm{kDa}$, which was confirmed by WB of the bovine recombinant PRAMEY. However, our efforts to explain the expression of the $30 \mathrm{kDa}$ PRAMEY isoform in the testes and spermatozoa was complicated by the fact that PRAMEY is a multicopy gene on the $Y$ chromosome (Yue et al. 2013) whose sequence has not been fully assembled in the bovine genome (Chang et al. 2011, 2013). It is possible that the $30 \mathrm{kDa}$ isoform might be translated from a PRAMEY transcript variant, or could be the result of a PRAMEY post-translational modification. These possibilities need to be further investigated. In humans, the PRAME protein has been well studied in melanoma cell lines and K562 cells (Costessi et al. 2011) and confirmed to be a protein of $58 \mathrm{kDa}$ molecular weight. However, a $70 \mathrm{kDa}$ protein was detected in human semen and sperm samples when the same antibody (kindly provided by Dr René Bernards) used in the previous melanoma cell study (Epping et al. 2005) was applied in our WB analysis. 
A similar result was obtained when a commercially available human PRAME antibody (Aviva systems biology, ARP55981_P050) that targets a different region of the human PRAME was applied (unpublished data). In mice, the predicted $57 \mathrm{kDa}$ PRAMEL1 was detected by a PRAMEL1-specific antibody in the testis, while a minor band of $42 \mathrm{kDa}$ was also observed (Mistry et al. 2013). The mouse OOG1 (Oogenesin 1), a paralog of PRAME, with a predicted intact protein of $57 \mathrm{kDa}$, was detected as a single $46 \mathrm{kDa}$ polypeptide in oocytes, one-cell and two-cell embryos, while two polypeptides $(57 \mathrm{kDa}$ and $46 \mathrm{kDa})$ were detected in four-cell embryos (Minami et al. 2003). These data suggest that members of the PRAME/PRAMEY family may undergo posttranslational modification during spermatogenesis, oogenesis and early embryo development. Therefore, the post-translational modification is likely important for the functioning of PRAME/PRAMEY.

\section{PRAMEY and the development of germinal granules}

Both IMC and CB are referred to as germinal granules, also known as nuage, a mammalian spermatogenetic cellspecific organelle, which was discovered in 1876 (von Brunn 1876) (see review by Sadaki Yokota (Yokota 2008) and Meikar et al. (Meikar et al. 2011)). IMC is found in the cytoplasm of spermatocytes and it disappears during meiosis, whereas the $\mathrm{CB}$ is present in the cytoplasm of post-meiotic spermatids. The relationship between IMC and CB has been studied for many decades and is still unclear. It was proposed in the 1970s that the CB originated from the dense material of the IMC (Fawcett et al. 1970). Recent IEM studies strongly support the previous proposal because several protein markers, including DDX4 (DEAD box polypeptide 4; also known as mouse VASA homolog, MVH) (Noce et al. 2001, Onohara et al. 2010) and Tudor domain containing 1 (TDRD-1) (Chuma et al. 2003), have been detected in both IMC and CB. However, since the IMC has already disappeared in spermatocytes while the $\mathrm{CB}$ forms in spermatids in Tdrd-1-null mice (Chuma et al. 2006), it raised a question of the importance of the IMC in the formation of the CB. In the present study, we found that bovine PRAMEY is a novel germinal granule-associated protein, which has not been discovered in mammalian CBs in previous transcriptome and proteomic analyses (Meikar et al. 2014). Similar to the mouse DDX4, the bovine PRAMEY is localized in all development stages of germinal granules (Fig. 9). Unlike DDX4 and the other IMC/CB proteins (such as TRDR1, MIWI, ubiquitin, ubiquitin-conjugating enzyme (E2), and proteasome activator PA700) that have a dispersed IEM labeling pattern in IMC/CB (Haraguchi et al. 2005, Yokota 2008), PRAMEY has a distinctively clustered labeling pattern in all stages of germinal granule, suggesting that the PRAMEY protein complex is somehow distinct from those previously investigated complexes.
We did not observe any nuage-like structure in bovine spermatogonia and early spermatocytes except for the PRAMEY-labeled small electron-dense particles in the cytoplasm, consistent with previous reports (Eddy 1974, Onohara et al. 2010). In late spermatocyte and early spermatids, a high density of the PRAMEY labeling was observed in the IMC electron-dense cement throughout the life of IMC. Differing from previous observations that IMC disappeared during meiosis and CB appeared first in early spermatids (reviewed by Onohara \& Yokota 2012), we observed a transitional stage of IMC in early spermatids in which the typical IMC disassembled and the mitochondria dissociated from PRAMEY-labeled electron-dense cement. The latter develops into the CB. Thus, the PRAMEY labeling strongly supports the previous proposal that the $\mathrm{CB}$ is derived from the IMC (Fawcett et al. 1970).

In previous studies, two distinct components of CB were observed during meiosis II in rats (Russell \& Frank 1978) and in step 2 spermatids in cattle (Barth \& Oko 1989). The two components were confirmed in this study and named as type I and II CB. The type I CB has the typical irregularly shaped CB structure that has been identified in all mammalian species studied. The type I CBs were present from step 1 to step 9 spermatids and became the late $\mathrm{CB}$ in the elongated spermatids (steps 10-14) in cattle (Berndston \& Desjardins 1974), consistent with the previous description of development of CBs in rodents (Susi \& Clermont 1970, Onohara et al. 2010). The type II CB had a round honeycomb-like structure and was reported previously in rats, mice and cattle (Brokelmann 1963, Gardner 1966, Barth \& Oko 1989). It is unclear whether the type II CB is a lineagespecific germinal granule, and if there is any difference in function between the two types of CBs. Further study on the emerging and disappearance of the type II CB may help to address these questions.

Satellite body (SB) was discovered in the 1970s and localized adjacent to the CB in the cytoplasm of secondary spermatocytes and young spermatids (Sud 1961, Fawcett et al. 1970, Russell \& Frank 1978). SB was found to be different from CB by its shape and molecular contents (Fawcett et al. 1970, Russell \& Frank 1978). SB was moderately labeled by the anti-Argonaute 2 (AGO2) antibody in rats (Fujii et al. 2016), and was very weakly labeled by anti-DDX4 antibody in mice, but not in rats and guinea pigs (Onohara et al. 2010). In this work, we noticed that the initial stage of the type II CB was similar to an SB in size, shape and location. Because the heavily labeled PRAMEY protein complex was observed in all stages during the development of the type II CB, we were able to link the initial SB-like body with the mature honeycomb-like CB. Although we did not find a SB in the bovine spermatogenic cells, the fate of the $\mathrm{SB}$ and the relationship between the $\mathrm{SB}$ and the type II CB in rodents and other species need to be investigated at the ultrastructural level by IEM. 
The mitochondria-associated granule was observed in the late spermatids by Clermont and coworkers (Clermont et al. 1990, 1993) and was named as MAG by Onohara and coworkers (Onohara et al. 2010). The granular materials of the MAG are similar to that of IMC in the pachytene spermatocytes, and were labeled by anti-DDX4, -AGO2, -CELF1 (CUGBP, Elav-like family member 1) and anti-Maelström (MAEL) antibodies in rats and/or mice (Onohara et al. 2010, Yonetamari et al. 2012, Fujii et al. 2016). In the present study, we found that the bovine PRAMEY protein localized intensely in the MAG, similar to the previous findings in rodents (Onohara et al. 2010, Fujii et al. 2016). Although the function of the MAG is still unknown, it is probable that it has a function similar to those of the other germinal granules, and may be involved in the formation of the mitochondrial sheath in the sperm flagellum.

Germinal granules are the characteristics of spermatogenetic cells in mammals. The molecular mechanism underlying the formation and the fate of germinal granules is not fully understood. The IEM data from this work suggest that PRAMEY and its associated proteins may provide a unique opportunity to address questions such as how IMC is initiated, how it transforms into $C B$ and how it becomes the late $C B$, and what is the relationship between late $C B$ and MAG. Such knowledge is essential to fully understand the molecular mechanism of spermatogenesis.

\section{Involvement of PRAMEY in acrosomal biogenesis}

Acrosome biogenesis is an important aspect of spermatogenesis; the molecular mechanism that regulates this event is not fully understood. The immunofluorescent staining pattern of PRAMEY on the bovine testis sections and spermatogenic cells clearly indicated that PRAMEY was localized in the AG in early steps of spermatid development and then in the $\mathrm{AC}$ of elongating and elongated spermatids, and testicular and epididymal spermatozoa. Based on the PRAMEY staining pattern, the bovine spermatozoa could be possibly divided into three subgroups: 'AC', 'AC\&ES-PAS' and 'ES-PAS'. We tend to believe that the 'AC' group with an intact and completely stained AC was the most common 'pre-capacitation' state, while the 'AC\&ES-PAS' and 'ES-PAS' may be undergoing capacitation. This concept is supported by the 'AC' staining pattern, similar to the one from the bovine anti-IZUMO1 (izumo sperm-egg fusion 1) staining before capacitation and the 'ES-PAS' pattern, similar to the one after capacitation (Nagdas et al. 2016). The localization of PRAMEY in the 'ES-PAS' junction could be important for the sperm-egg binding and fertilization. In fact, our preliminary data has demonstrated that PRAMEY may be involved in polyspermy (unpublished data).

In line with the immunofluorescent staining results, our IEM data further defined the localization of PRAMEY at a subcellular level during AC biogenesis (summarized

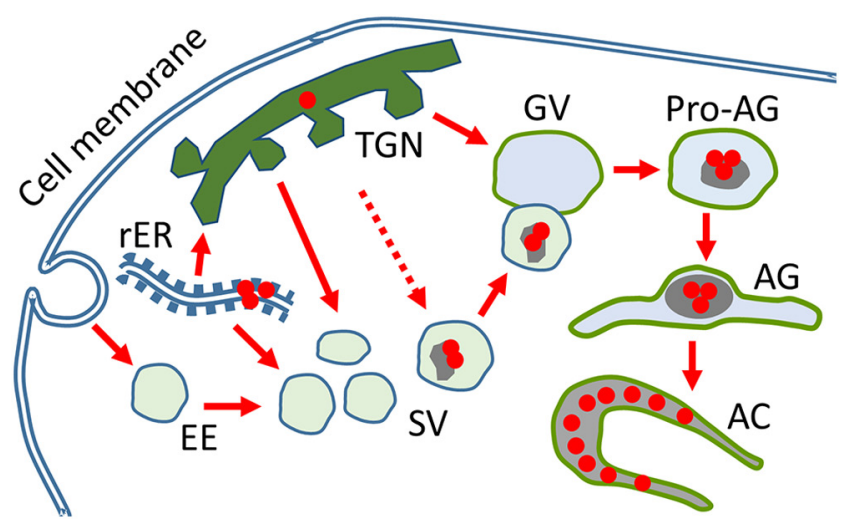

Figure 10 A schematic representation of the 'ER-Golgi-acrosome' biosynthetic transport system (modified from reference Berruti \& Paiardi 2011). Solid arrows indicate the development and formation of the acrosome. Dashed arrow shows the possible involvement of the trans-Golgi network (TGN) in the formation of the small vesicles with PRAMEY-labeled granules (Fig. 3E).

in Fig. 9). We could clearly trace the PRAMEY-labeled electron-dense materials in the small vesicles, initially observed in spermatocytes, and their fusion with a large unlabeled vesicle in steps 1-2 spermatids and the formation of the AG thereafter in step 3 spermatids. Our data is in agreement with the previous discovery on the development of GV and AG (Barth \& Oko 1989), supporting a previous hypothesis that protein trafficking is the core in the 'ER-Golgi-acrosome' biosynthetic transport system (Berruti \& Paiardi 2011) (Fig. 10). A molecular motor, kinesin family member C1 (KIFC1), is associated with the acrosome and manchette in developing spermatids (Yang \& Sperry 2003, Wang \& Sperry 2008, Yu et al. 2009), and functions in vesicle trafficking from the Golgi to AC during AC biogenesis (Yang \& Sperry 2003, Berruti \& Paiardi 2011). In the manchette, KIFC1 serves a structural role to transport molecules along the microtubules by interacting with a LRR protein, PPP1R42 (Yang \& Sperry 2003, Wang et al. 2010). The latter was found to bind strongly to PP1 $\gamma 2$ and was suggested to act as a scaffold (Shaw \& Filbert 2009) to connect diverse signaling molecules for spermatid transformation (Wang et al. 2010). Importantly, our results indicate that PRAMEY is also a testis-specific LRR protein (Chang et al. 2011), which also interacts with PP1 $\gamma 2$ (Fig. 1D). As PRAMEY is mainly localized in microtubule-containing organelles, including manchette, it will be interesting if future research demonstrates that PRAMEY and KIFC1 function interactively during AC biogenesis.

Unlike the non-acrosomal organelles within which the anti-PRAMEY labeling was clustered in groups, the AG in the cap phase and the early acrosomal phase had a very unique labeling pattern, i.e. single gold particles were arranged in a 'string of beads' as part of the filament-like material in the AG matrix (Fig. $7 \mathrm{C}$ ). 
The AG matrix expands during the cap and acrosomal phase, and transforms into the AM during the maturation phase. As the anti-PRAMEY labeling in the AM of mature spermatozoa is still maintained in the 'string of beads' pattern in the peri-IAM region (Fig. 7F), we believe that the PRAMEY-associated network is part of the essential structure for the spatial segregation of matrix components. These components were discussed in previous studies with a proposed function of defining the distribution of selected hydrolases in AC (Olson et al. 1988, Foster et al. 1997, Hermo et al. 2010). A recent proteomic analysis on the mouse epididymal sperm identified a total of 1026 AM proteins that include primarily proteases, chaperones, hydrolases, transporters, enzyme modulators, transferases and cytoskeletal proteins (Guyonnet et al. 2012). However, none of the proteins in the PRAME family was discovered in this analysis, inconsistent with the recent localization of the mouse PRAMEL1 to the AC (Mistry et al. 2013). To date, a very small number of $A M$ proteins, including the guinea pig AM50; the mouse ACR, GRN and CRISP2 (Hardy et al. 1988, Anakwe et al. 1991, Baba et al. 1993, WestbrookCase et al. 1995, Foster \& Gerton 1996); and another CTA protein, CAGE1 (cancer antigen 1) (Alsheimer et al. 2005), have been localized ultrastructurally by IEM. All of them were localized in both the AV and AG of round spermatids and the AM in spermatozoa. However, the human prion protein doublet (PRND) was localized in the $A V$ and $A G$ in round spermatids but not in elongated spermatids and spermatozoa (Serres et al. 2006). Thus, the exclusive localization of the bovine PRAMEY in AG, but not in $\mathrm{AV}$, of round spermatids and early elongated spermatids suggest that PRAMEY has a distinct function from the other AM proteins.

\section{Supplementary data}

This is linked to the online version of the paper at http://dx.doi. org/10.1530/REP-17-0013.

\section{Declaration of interest}

The authors declare that there is no conflict of interest that could be perceived as prejudicing the impartiality of the research reported.

\section{Funding}

This work was supported, in part, by the National Institute of Food and Agriculture (NIFA), USDA (grant no. 2010-6520520362) and by a TSF-CURE grant from the Pennsylvania Department of Health.

\section{Acknowledgments}

The authors would like to thank Dr Richard G Saacke at Virginia Polytechnic Institute and State University for his assistance in interpreting of the electron microscopic images and for his constructive comments on the draft manuscript. The authors are grateful to $\operatorname{Dr}$ Daniel Kniffen at the Pennsylvania State University and Mr Douglas Nicholas at Nicholas Meat Packing Co. (Loganton, PA, USA) for providing bovine testicular tissues.

\section{References}

Alsheimer M, Drewes T, Schutz W \& Benavente R 2005 The cancer/ testis antigen CAGE-1 is a component of the acrosome of spermatids and spermatozoa. European Journal of Cell Biology 84 445-452. (doi:10.1016/j.ejcb.2004.11.003)

Anakwe OO \& Gerton GL 1990 Acrosome biogenesis begins during meiosis: evidence from the synthesis and distribution of an acrosomal glycoprotein, acrogranin, during guinea pig spermatogenesis. Biology of Reproduction 42 317-328. (doi:10.1095/biolreprod42.2.317)

Anakwe OO, Sharma S, Hoff HB, Hardy DM \& Gerton GL 1991 Maturation of guinea pig sperm in the epididymis involves the modification of proacrosin oligosaccharide side chains. Molecular Reproduction and Development 29 294-301. (doi:10.1002/mrd.1080290313)

Baba T, Hoff HB 3rd, Nemoto H, Lee H, Orth J, Arai Y \& Gerton GL 1993 Acrogranin, an acrosomal cysteine-rich glycoprotein, is the precursor of the growth-modulating peptides, granulins, and epithelins, and is expressed in somatic as well as male germ cells. Molecular Reproduction and Development 34 233-243. (doi:10.1002/mrd.1080340302)

Barth AD \& Oko RJ 1989 Abnormal Morphology of Bovine Spermatozoa. Ames, lowa: lowa State University Press.

Berndston WE \& Desjardins C 1974 The cycle of the seminiferous epithelium and spermatogenesis in the bovine testis. American Journal of Anatomy 140 167-179. (doi:10.1002/aja.1001400204)

Berruti G \& Paiardi C 2011 Acrosome biogenesis: revisiting old questions to yield new insights. Spermatogenesis 1 95-98. (doi:10.4161/ spmg.1.2.16820)

Birtle Z, Goodstadt L \& Ponting C 2005 Duplication and positive selection among hominin-specific PRAME genes. BMC Genomics $\mathbf{6} 120$. (doi:10.1186/1471-2164-6-120)

Brokelmann J 1963 Fine structure of germ cells and Sertoli cells during the cycle of the seminiferous epithelium in the rat. Zeitschrift Fur Zellforschung Und Mikroskopische Anatomie 59 820-850. (doi:10.1007/ BF00362263)

Buffone MG, Kim KS, Doak BJ, Rodriguez-Miranda E \& Gerton GL 2009 Functional consequences of cleavage, dissociation and exocytotic release of ZP3R, a C4BP-related protein, from the mouse sperm acrosomal matrix. Journal of Cell Science 122 3153-3160. (doi:10.1242/ jcs.052977)

Chang TC, Yang Y, Yasue H, Bharti AK, Retzel EF \& Liu WS 2011 The expansion of the PRAME gene family in Eutheria. PLOS ONE 6 e16867. (doi:10.1371/journal.pone.0016867)

Chang TC, Yang Y, Retzel EF \& Liu WS 2013 Male-specific region of the bovine $\mathrm{Y}$ chromosome is gene rich with a high transcriptomic activity in testis development. PNAS 110 12373-12378. (doi:10.1073/ pnas.1221104110)

Cheng YH, Wong EW \& Cheng CY 2011 Cancer/testis (CT) antigens, carcinogenesis and spermatogenesis. Spermatogenesis 1 209-220. (doi:10.4161/spmg.1.3.17990)

Chuma S, Hiyoshi M, Yamamoto A, Hosokawa M, Takamune K \& Nakatsuji N 2003 Mouse Tudor Repeat-1 (MTR-1) is a novel component of chromatoid bodies/nuages in male germ cells and forms a complex with snRNPs. Mechanisms of Development 120 979-990. (doi:10.1016/ S0925-4773(03)00181-3)

Chuma S, Hosokawa M, Kitamura K, Kasai S, Fujioka M, Hiyoshi M, Takamune K, Noce T \& Nakatsuji N 2006 Tdrd1/Mtr-1, a tudor-related gene, is essential for male germ-cell differentiation and nuage/germinal granule formation in mice. PNAS 103 15894-15899. (doi:10.1073/ pnas.0601878103)

Clermont Y, Oko R \& Hermo L 1990 Immunocytochemical localization of proteins utilized in the formation of outer dense fibers and fibrous sheath in rat spermatids: an electron microscope study. Anatomical Record 227 447-457. (doi:10.1002/ar.1092270408) 
Clermont Y, Oko R \& Hermo L 1993 Cell biology of mammalian spermiogenesis. In Cell and Molecular Biology of the Testis, pp 332-376. Eds C Desjardins \& LL Ewing. New York: Oxford University Press.

Coonrod SA, Herr JC \& Westhusin ME 1996 Inhibition of bovine fertilization in vitro by antibodies to SP-10. Journal of Reproduction and Fertility 107 287-297. (doi:10.1530/jrf.0.1070287)

Costessi A, Mahrour N, Tijchon E, Stunnenberg R, Stoel MA, Jansen PW, Sela D, Martin-Brown S, Washburn MP, Florens L et al. 2011 The tumour antigen PRAME is a subunit of a Cul2 ubiquitin ligase and associates with active NFY promoters. EMBO Journal 30 3786-3798. (doi:10.1038/ emboj.2011.262)

Eddy EM 1974 Fine structural observations on the form and distribution of nuage in germ cells of the rat. Anatomical Record 178 731-757. (doi:10.1002/ar.1091780406)

Epping MT, Wang L, Edel MJ, Carlee L, Hernandez M \& Bernards R 2005 The human tumor antigen PRAME is a dominant repressor of retinoic acid receptor signaling. Cell 122 835-847. (doi:10.1016/j.cell.2005.07.003)

Epping MT, Wang L, Plumb JA, Lieb M, Gronemeyer H, Brown R \& Bernards R 2007 A functional genetic screen identifies retinoic acid signaling as a target of histone deacetylase inhibitors. PNAS $\mathbf{1 0 4}$ 17777-17782. (doi:10.1073/pnas.0702518104)

Fardilha M, Esteves SL, Korrodi-Gregorio L, Pelech S, da Cruz ESOA \& da Cruz ESE 2011 Protein phosphatase 1 complexes modulate sperm motility and present novel targets for male infertility. Molecular Human Reproduction 17 466-477. (doi:10.1093/molehr/gar004)

Fawcett DW, Eddy EM \& Phillips DM 1970 Observations on the fine structure and relationships of the chromatoid body in mammalian spermatogenesis. Biology of Reproduction 2 129-153. (doi:10.1095/ biolreprod2.1.129)

Foster JA \& Gerton GL 1996 Autoantigen 1 of the guinea pig sperm acrosome is the homologue of mouse Tpx-1 and human TPX1 and is a member of the cysteine-rich secretory protein (CRISP) family. Molecular Reproduction and Development 44 221-229. (doi:10.1002/(SICI)10982795(199606)44:2<221::AID-MRD11>3.0.CO;2-5)

Foster JA, Friday BB, Maulit MT, Blobel C, Winfrey VP, Olson GE, Kim KS \& Gerton GL 1997 AM67, a secretory component of the guinea pig sperm acrosomal matrix, is related to mouse sperm protein sp56 and the complement component 4-binding proteins. Journal of Biological Chemistry 272 12714-12722. (doi:10.1074/jbc.272.19.12714)

Fujii Y, Onohara Y, Fujita H \& Yokota S 2016 Argonaute 2 protein in rat spermatogenic cells is localized to nuage structures and LAMP2-positive vesicles surrounding chromatoid bodies. Journal of Histochemistry and Cytochemistry 64 268-279. (doi:10.1369/0022155416638840)

Gardner PJ 1966 Fine structure of the seminiferous tubule of the Swiss mouse. The spermatid. Anatomical Record 155 235-249. (doi:10.1002/ ar.1091550210)

Grootegoed JA, Baarends WM, Hendriksen PJ, Hoogerbrugge JW, Slegtenhorst-Eegdeman KE \& Themmen AP 1995 Molecular and cellular events in spermatogenesis. Human Reproduction 10 (Supplement 1) 10-14. (doi:10.1093/humrep/10.suppl_1.10)

Guyonnet B, Zabet-Moghaddam M, SanFrancisco S \& Cornwall GA 2012 Isolation and proteomic characterization of the mouse sperm acrosomal matrix. Molecular and Cellular Proteomics 11 758-774. (doi:10.1074/ mcp.M112.020339)

Gwathmey TM, Ignotz GG \& Suarez SS 2003 PDC-109 (BSP-A1/A2) promotes bull sperm binding to oviductal epithelium in vitro and may be involved in forming the oviductal sperm reservoir. Biology of Reproduction 69 809-815. (doi:10.1095/biolreprod.102.010827)

Haraguchi CM, Mabuchi T, Hirata S, Shoda T, Hoshi K, Akasaki K \& Yokota S 2005 Chromatoid bodies: aggresome-like characteristics and degradation sites for organelles of spermiogenic cells. Journal of Histochemistry and Cytochemistry 53 455-465. (doi:10.1369/ jhc.4A6520.2005)

Hardy DM, Huang TT Jr, Driscoll WJ, Tung KK \& Wild GC 1988 Purification and characterization of the primary acrosomal autoantigen of guinea pig epididymal spermatozoa. Biology of Reproduction 38 423-437. (doi:10.1095/biolreprod38.2.423)

Hermo L, Pelletier RM, Cyr DG \& Smith CE 2010 Surfing the wave, cycle, life history, and genes/proteins expressed by testicular germ cells. Part 2: changes in spermatid organelles associated with development of spermatozoa. Microscopy Research and Technique 73 279-319. (doi:10.1002/jemt.20787)
Huang Z, Khatra B, Bollen M, Carr DW \& Vijayaraghavan S 2002 Sperm PP1gamma2 is regulated by a homologue of the yeast protein phosphatase binding protein sds22. Biology of Reproduction 67 1936-1942. (doi:10.1095/biolreprod.102.004093)

Kawa S, Ito C, Toyama Y, Maekawa M, Tezuka T, Nakamura T, Nakazawa T, Yokoyama K, Yoshida N, Toshimori K et al. 2006 Azoospermia in mice with targeted disruption of the Brek/Lmtk2 (brain-enriched kinase/ lemur tyrosine kinase 2) gene. PNAS 103 19344-19349. (doi:10.1073/ pnas.0603603103)

Kurth BE, Wright RM, Flickinger CJ \& Herr JC 1993 Stage-specific detection of mRNA for the sperm antigen SP-10 in human testes. Anatomical Record 236 619-625. (doi:10.1002/ar.1092360405)

Maunsbach A \& Afzelius B 1998 Biomedical Electron Microscopy: Illustrated Methods and Interpretations, 1st ed. Academic Press. London, UK:

Meikar O, Da Ros M, Korhonen H \& Kotaja N 2011 Chromatoid body and small RNAs in male germ cells. Reproduction 142 195-209. (doi:10.1530/REP-11-0057)

Meikar O, Vagin VV, Chalmel F, Sostar K, Lardenois A, Hammell M, Jin Y, Da Ros M, Wasik KA, Toppari J, Hannon GJ et al. 2014 An atlas of chromatoid body components. RNA 20 483-495. (doi:10.1261/ rna.043729.113)

Meuwissen RL, Offenberg HH, Dietrich AJ, Riesewijk A, van Iersel M \& Heyting C 1992 A coiled-coil related protein specific for synapsed regions of meiotic prophase chromosomes. EMBO Journal 11 5091-5100.

Minami N, Aizawa A, Ihara R, Miyamoto M, Ohashi A \& Imai H 2003 Oogenesin is a novel mouse protein expressed in oocytes and early cleavage-stage embryos. Biology of Reproduction 69 1736-1742. (doi:10.1095/biolreprod.103.018051)

Mishra S, Somanath PR, Huang Z \& Vijayaraghavan S 2003 Binding and inactivation of the germ cell-specific protein phosphatase PP1gamma2 by sds22 during epididymal sperm maturation. Biology of Reproduction 69 1572-1579. (doi:10.1095/biolreprod.103.018739)

Mistry BV, Zhao Y, Chang TC, Yasue H, Chiba M, Oatley J, Diaz F \& Liu WS 2013 Differential expression of PRAMEL1, a cancer/testis antigen, during spermatogenesis in the mouse. PLOS ONE 8 e60611. (doi:10.1371/ journal.pone.0060611)

Nagdas SK, Smith L, Medina-Ortiz I, Hernandez-Encarnacion L \& Raychoudhury S 2016 Identification of bovine sperm acrosomal proteins that interact with a $32-\mathrm{kDa}$ acrosomal matrix protein. Molecular and Cellular Biochemistry 414 153-169. (doi:10.1007/s11010-016-2668-3)

Noce T, Okamoto-Ito S \& Tsunekawa N 2001 Vasa homolog genes in mammalian germ cell development. Cell Structure and Function 26 131-136. (doi:10.1247/csf.26.131)

Olson GE, Winfrey VP \& Davenport GR 1988 Characterization of matrix domains of the hamster acrosome. Biology of Reproduction 39 1145-1158. (doi:10.1095/biolreprod39.5.1145)

Onohara Y \& Yokota S 2012 Nuage components and their contents in mammalian spermatogenic cells, as revealed by immunoelectron microscopy. In Meiosis - Molecular Mechanisms and Cytogenetic Diversity, pp 217-240. Ed A Swan. Croatia: InTech.

Onohara Y, Fujiwara T, Yasukochi T, Himeno M \& Yokota S 2010 Localization of mouse vasa homolog protein in chromatoid body and related nuage structures of mammalian spermatogenic cells during spermatogenesis. Histochemistry and Cell Biology 133 627-639. (doi:10.1007/s00418010-0699-5)

Russell L \& Frank B 1978 Ultrastructural characterization of nuage in spermatocytes of the rat testis. Anatomical Record 190 79-97. (doi:10.1002/ar.1091900108)

Saburi S, Nadano D, Akama TO, Hirama K, Yamanouchi K, Naito K, Tojo H, Tachi C \& Fukuda MN 2001 The trophinin gene encodes a novel group of MAGE proteins, magphinins, and regulates cell proliferation during gametogenesis in the mouse. Journal of Biological Chemistry 276 49378-49389. (doi:10.1074/jbc.M108584200)

Serres C, Peoc'h K, Courtot AM, Lesaffre C, Jouannet P \& Laplanche JL 2006 Spatio-developmental distribution of the prion-like protein doppel in Mammalian testis: a comparative analysis focusing on its presence in the acrosome of spermatids. Biology of Reproduction 74 816-823. (doi:10.1095/biolreprod.105.047829)

Shaw AS \& Filbert EL 2009 Scaffold proteins and immune-cell signalling. Nature Reviews Immunology 9 47-56. (doi:10.1038/nri2473) 
Shetty J, Diekman AB, Jayes FC, Sherman NE, Naaby-Hansen S, Flickinger CJ \& Herr JC 2001 Differential extraction and enrichment of human sperm surface proteins in a proteome: identification of immunocontraceptive candidates. Electrophoresis 22 3053-3066. (doi:10.1002/15222683(200108)22:14<3053::AID-ELPS3053>3.0.CO;2-K)

Simpson AJ, Caballero OL, Jungbluth A, Chen YT \& Old LJ 2005 Cancer/ testis antigens, gametogenesis and cancer. Nature Reviews Cancer $\mathbf{5}$ 615-625. (doi:10.1038/nrc1669)

Smith GD, Wolf DP, Trautman KC, da Cruz e Silva EF, Greengard P \& Vijayaraghavan S 1996 Primate sperm contain protein phosphatase 1, a biochemical mediator of motility. Biology of Reproduction 54 719-727. (doi:10.1095/biolreprod54.3.719)

Sud BN 1961 Morphological and cytochemical studies of the chromatoid body and related elements in the spermatogenesis of the rat. Quarterly Journal of Microscopical Science 102 495-505.

Susi FR \& Clermont Y 1970 Fine structural modifications of the rat chromatoid body during spermiogenesis. American Journal of Anatomy 129 177-191. (doi:10.1002/aja.1001290205)

Susi FR, Leblond CP \& Clermont Y 1971 Changes in the golgi apparatus during spermiogenesis in the rat. American Journal of Anatomy $\mathbf{1 3 0}$ 251-267. (doi:10.1002/aja.1001300302)

von Brunn A 1875 Beiträge zur entwicklungsgeschichte der samenkörper. Archiv Für Mikroskopische Anatomie 12 528-535. (doi:10.1007/ bf02933904)

Wang R \& Sperry AO 2008 Identification of a novel Leucine-rich repeat protein and candidate PP1 regulatory subunit expressed in developing spermatids. BMC Cell Biology 9 9. (doi:10.1186/1471-2121-9-9)

Wang R, Kaul A \& Sperry AO 2010 TLRR (Irrc67) interacts with PP1 and is associated with a cytoskeletal complex in the testis. Biology of the Cell 102 173-189. (doi:10.1042/BC20090091)

Westbrook-Case VA, Winfrey VP \& Olson GE 1995 Sorting of the domainspecific acrosomal matrix protein AM50 during spermiogenesis in the guinea pig. Developmental Biology 167 338-349. (doi:10.1006/ dbio.1995.1028)

Yang WX \& Sperry AO 2003 C-terminal kinesin motor KIFC1 participates in acrosome biogenesis and vesicle transport. Biology of Reproduction 69 1719-1729. (doi:10.1095/biolreprod.102.014878)

Yokota S 2008 Historical survey on chromatoid body research. Acta Histochemica et Cytochemica 41 65-82. (doi:10.1267/ahc.08010)

Yonetamari H, Onohara Y \& Yokota S 2012 Localization of BRUNOL2 in rat spermatogenic cells as revealed by immunofluorescence and immunoelectron microscopic techniques. Open Journal of Cell Biology 2 11-20. (doi:10.4236/ojcb.2012.22002)

Yu K, Hou L, Zhu JQ, Ying XP \& Yang WX 2009 KIFC1 participates in acrosomal biogenesis, with discussion of its importance for the perforatorium in the Chinese mitten crab Eriocheir sinensis. Cell and Tissue Research 337 113-123. (doi:10.1007/s00441-0090800-3)

Yue XP, Chang TC, Dejarnette JM, Marshall CE, Lei CZ \& Liu WS 2013 Copy number variation of PRAMEY across breeds and its association with male fertility in Holstein sires. Journal of Dairy Science $\mathbf{9 6}$ 8024-8034. (doi:10.3168/jds.2013-7037)

Zhou J, McCarrey JR \& Wang PJ 2013 A 1.1-Mb segmental deletion on the $\mathrm{X}$ chromosome causes meiotic failure in male mice. Biology of Reproduction 88 159. (doi:10.1095/biolreprod.112.106963)

Received 9 January 2017

First decision 13 February 2017

Revised manuscript received 6 March 2017

Accepted 29 March 2017 